\title{
One- and two-dimensional cuprous oxide nano/micro structures fabricated on highly orientated pyrolytic graphite (HOPG) by electrodeposition
}

\author{
S.Y. $\mathrm{Ng}^{\S}$ and A.H.W. Ngan \\ Department of Mechanical Engineering, \\ The University of Hong Kong, \\ Pokfulam Road, Hong Kong, P.R. China \\ ${ }^{\S}$ Corresponding Author (Email: angeln@hku.hk)
}

One- and two-dimensional cuprous oxide $\left(\mathrm{Cu}_{2} \mathrm{O}\right)$ nanostructures were fabricated on highly orientated pyrolytic graphite (HOPG) by electrodeposition in $\mathrm{CuSO}_{4}$ at room temperature $\left(25^{\circ} \mathrm{C}\right)$ with no additives. For short deposition times, $1 \mathrm{D} \mathrm{Cu}_{2} \mathrm{O}$ single nanocrystals were generally of an octahedral shape with sizes ranging from 50nm to $400 \mathrm{~nm}$, while $2 \mathrm{D} \mathrm{Cu}_{2} \mathrm{O}$ nanowires with diameters ranging from $100 \mathrm{~nm}$ to $300 \mathrm{~nm}$ had lengths of more than $100 \mu \mathrm{m}$. With longer deposition times, microwires were found to have diameters ranging from $1 \mu \mathrm{m}$ to $2 \mu \mathrm{m}$ with lengths up to $60 \mu \mathrm{m}$, while microcrystals were also produced with sizes $1 \mu \mathrm{m}$ to $6 \mu \mathrm{m}$. The highly aligned $\mathrm{Cu}_{2} \mathrm{O}$ nano/microwires were found to be deposited on the step edges of the HOPG substrate. Various crystal morphologies including flower-like and butterfly-like structures, and dendrites and truncated octahedra were observed on the working 
electrode of HOPG. Some of the morphologies are revealed for the first time by one step electrodeposition and these are confirmed to be single $\mathrm{Cu}_{2} \mathrm{O}$ crystals.

Keywords: Cuprous oxide; Single crystals; $\mathrm{Cu}_{2} \mathrm{O}$ nanowires; HOPG;

Electrodeposition 


\section{Introduction}

Nanostructured semiconductors are an emerging research area as they are expected to exhibit superior performance due to their remarkable structural, electrical and optical properties. Cuprous oxide $\left(\mathrm{Cu}_{2} \mathrm{O}\right)$ is a non-toxic p-type semiconductor with a direct band gap of around $2.1 \mathrm{eV}$ [1]. Owing to its photovoltaic properties, its use in many applications, such as catalyst for decomposition of water [2], conversion of organic contaminants [3], solar energy conversion, electrochemical photovoltaic cells, gas sensors, nano/microelectronics and electrode material for lithium ion batteries [4 - 8], has been demonstrated.

A number of methods, for example, physical vapor deposition [9], solution-phase synthesis [10] and thermal decomposition [11], have been developed to prepare nanostructured materials. Among these, electrodeposition is well known as one of the most efficient and effective methods, because it is a simple and low-cost process, yet production rate can be high and the size and shape of the substrate are less limited [12-13]. More specifically, electrodeposition on substrates with atomic sized step edges, known as electrochemical step-edge decoration (ESED) [14], is one of the most widely used methods for fabricating nanowires. Highly oriented pyrolytic graphite (HOPG), a type of high-purity graphite, is a widely used substrate material for ESED, because its atomic steps of around 0.2-0.3nm high can often provide chemically active sites for the deposition of nanostructures. 
Penner and co-workers [12] proposed the three-step potentiostatic pulse electrodeposition method which includes the "oxidation", "nucleation" and "growth" steps in on HOPG. Zach et al. [15] electrodeposited $\mathrm{MoO}_{\mathrm{x}}$ nanowires on the step edges of HOPG and further reduced them to form Mo nanowires. Mukhopadhyay and Freyland [16] reported the preparation of $\mathrm{Ti}$ nanowires from ionic liquid by electrodeposition. Other nanowire materials such as nickel, copper, silver, gold, zinc, silicon, palladium, cadmium sulfide and bismuth telluride have been synthesized on HOPG by electrodeposition [17-20]. Besides single metal nanowires, Tang et al. [21] and Xiao et. al [22] have successfully fabricated Pd-Ag and Pd-Ni alloy nanowire arrays respectively by using an aqueous plating solution. Electrodeposition can be used to fabricate not only single metal nanowires, but also beaded bimetallic nanowires. One type of metal nanoparticles is first electrodeposited and covered by self-assembled monolayer (SAM), and then by switching to another electrolyte and electrodepositing the second metal nanoparticles, bimetallic nanowires are formed [23]. The bimetallic nanowires synthesized include $\mathrm{Ag}-\mathrm{Cu}, \mathrm{Ag}-\mathrm{Fe}, \mathrm{Ag}-\mathrm{Pd}, \mathrm{Cu}-\mathrm{MoO}_{2}$, $\mathrm{Fe}-\mathrm{MoO}_{2}, \mathrm{Pt}-\mathrm{MoO}_{2}, \mathrm{Pd}-\mathrm{MoO}_{2}, \mathrm{Ni}-\mathrm{MoO}_{2}$ and $\mathrm{Au}-\mathrm{MoO}_{2}$.

The previous studies summarized above concerned the electrodeposition of metal or bimetallic nanowires, and reports on electrodeposition of metal oxide are very rare. Also, most of the previous studies made use of the three-step potentiostatic pulse electrodeposition method. In this paper, we report the fabrication of cuprous oxide 
nanowires on HOPG step edges using a single potentiostatic electrodeposition step at room temperature with a simple setup.

\section{Experimental methods}

The substrates used in this study were $20 \mathrm{~mm} \times 20 \mathrm{~mm} \times 1 \mathrm{~mm}$ highly orientated pyrolytic graphite (HOPG) sheets, graded SPI-2 (supplied by SPI supplies Ltd.). with an effective surface area of $200 \mathrm{~mm}^{2}$. The HOPG was cleaved with adhesive tape before electrodeposition.

The electrolyte was prepared by mixing analytical-grade copper (II) sulphate (supplied by Sigma Aldrich Co Ltd.) and distilled water to achieve a concentration of 0.018M. The electrolyte was ultrasonically treated for $10 \mathrm{~min}$ before the experiment to ensure good solubility.

A simple two-electrode system was used for this experiment. During electrodeposition, HOPG substrates were used as the working electrode (cathode) while a $0.5 \mathrm{~mm} \times 30 \mathrm{~mm} \times 50 \mathrm{~mm}$ polished copper plate (with purity $>99.9 \%$ ) was used as the counter and reference electrode (the anode). Since only about half of the HOPG sheet was immersed into the electrolyte, the effective cathode area was about $200 \mathrm{~mm}^{2}$. Both electrodes were connected to an electrochemical workstation (LK2006A, Lanlike) which acted as the power supply. The electrodes were separated 
by a distance of $15 \mathrm{~mm}$, and the whole electrodeposition process was conducted at room temperature. All experiments were carried out under constant voltage conditions. After electrodeposition, the substrates were rinsed several times with distilled water and ethanol, and were kept inside a desiccator at room temperature before characterization.

The morphology, chemical composition as well as crystal structure of the deposited nanowires and crystals were examined in a field-emission scanning electron microscope (FEG SEM, Hitachi S4800) equipped with energy-dispersive x-ray spectroscopy (EDX) analysis function, and a transmission electron microscope (Scanning TEM, FEI Tecnai G2 20) operating at 200kV. To allow TEM to be carried out, the deposited crystals and wires were desquamated from the substrates onto Formvar films supported by standard TEM copper sample grids. Electron backscattered diffraction (EBSD) was carried out at an acceleration voltage of $20 \mathrm{kV}$, working distance of $25 \mathrm{~mm}$ and a sample tilt angle of $70^{\circ}$ in a LEO 1530 FEG SEM. The EBSD patterns were automatically indexed and then analyzed using the CHANNEL 5 software package.

\section{Results}

\subsection{Nanostructure/microstructure characterization on HOPG}

\subsection{1. $\mathrm{Cu}_{2} \mathrm{O}$ nanocrystals and nanowires deposition}


Fig. 1(a) shows a low-magnification SEM image of the deposited nanocrystals and nanowires on a HOPG substrate. The applied electrodeposition voltage was $80 \mathrm{mV}$ for $60 \mathrm{~s}$. Arrays of long nanowires are shown deposited at the step edges of the HOPG and beside the nanowires, single nanocrystals were also uniformly distributed over the substrate surface. The nanocrystals observed had edge lengths ranging from 50nm to 400nm, and the higher magnification SEM image in Fig. 1(b) shows one of these with an octahedral shape and edge length $270 \mathrm{~nm}$. Most of the nanocrystals were octahedral or truncated octahedral in shape.

As shown in Fig. 1(a), the long nanowires deposited at the step edges are highly aligned, and many of them are continuous up to $100 \mu \mathrm{m}$ in length, although some are shorter, discrete segments. A portion of a long nanowire is shown in higher magnification in Fig. 1(c), which shows the continuity of the nanowire and the shape of the individual crystals making up the nanowire. The nanowires fabricated this way were therefore composed of truncated octahedral nanocrystals, i.e. they were "beaded" nanowires. Due to the granular morphology of these nanowires, their diameter varies by $\pm 30 \mathrm{~nm}$ throughout their length. The diameter of the particular nanowire in Fig. 1(c) was about 160nm, and that of all the nanowires observed was in the range from $100 \mathrm{~nm}$ to $300 \mathrm{~nm}$.

Fig. 2(a) shows a TEM bright-field image of a truncated octahedral nanocrystal 
desquamated from a HOPG substrate. Selected-area electron diffraction (SAED) carried out over the nanocrystal, Fig. 2(b), revealed the diffraction pattern of a cubic structure of the nanocrystal. Several layers of the HOPG were desquamated together with the nanocrystal on the copper grid as shown in Fig. 2(a) (the diagonal line in the middle of the figure shows a step of the HOPG) and therefore a set of dotty, concentric oval rings arising from the graphite were superimposed on the cubic diffraction pattern of the nanocrystal [24]. For the cubic structure, the SAED pattern in Fig. 2(b) was taken along its [011] zone, and by calculation, its lattice constant was determined to be $0.43 \pm 0.01 \mathrm{~nm}$, which is in agreement with the known value of $0.427 \mathrm{~nm}$ for $\mathrm{Cu}_{2} \mathrm{O}$ [25]. The nanocrystal was thus identified to be cuprous oxide $\mathrm{Cu}_{2} \mathrm{O}$. No grain boundary or changes in the crystal orientation could be detected from within the particle and it was thus confirmed to be a single nanocrystal. From the determined orientation of the crystal, the truncated faces in Fig. 2(a) were found to be $\{100\}$, and the eight faces of the truncated octahedron were found to be all $\{111\}$ planes. As the crystal continues to grow along the $\langle 100\rangle$ direction normal to the truncated $\{100\}$ faces, the latter may continue to shrink until they disappear at the apexes of a full octahedron.

\subsection{2. $\mathrm{Cu}_{2} \mathrm{O}$ microcrystals and microwires deposition}

At the same deposition voltage of $80 \mathrm{mV}$ but for longer deposition time of $300 \mathrm{~s}$, the deposited isolated crystals and beaded wires grow into the micron size, as shown 
in Fig. 3(a). The microwires were generally $1-2 \mu \mathrm{m}$ in diameter and up to $60 \mu \mathrm{m}$ in length. $\mathrm{A} \mathrm{Cu}_{2} \mathrm{O}$ microwire of diameter $1.0 \mu \mathrm{m}$ is shown in high magnification in Fig. 3(b), revealing the constituent octahedral shaped microcrystals along the wire length.

Fig. 4 shows a TEM bright-field image of a microwire fragment desquamated from a HOPG substrate. Three crystals each with octahedral shape comprised this fragment. The top row of SAED patterns in Fig. 4 were taken from each of the three crystals, at the same sample orientation along the [110] zone for the left crystal. The diffraction pattern of the left crystal shows a cubic crystal structure with lattice constant of $0.43 \pm 0.01 \mathrm{~nm}$ which is in agreement with that of $\mathrm{Cu}_{2} \mathrm{O}$. At this sample tilt, the other two crystals did not have a major zone aligned with the electron beam, and so their SAED patterns do not show characteristics of the cubic $\mathrm{Cu}_{2} \mathrm{O}$ structure. However, upon tilting the specimen to align a major zone of each of the two remaining crystals with the electron beam separately, they show again the cubic structure of $\mathrm{Cu}_{2} \mathrm{O}$. It can therefore be concluded that the microwires are "beaded" polycrystalline microwires comprising individual octahedral crystals of $\mathrm{Cu}_{2} \mathrm{O}$ with different orientations, and this applies to the $\mathrm{Cu}_{2} \mathrm{O}$ nanowires as well.

The microcrystals observed were of octahedral shapes and the edge length ranged from $1 \mu \mathrm{m}$ to $6 \mu \mathrm{m}$. Fig. 5(a) shows a SEM image of a typical octahedral $\mathrm{Cu}_{2} \mathrm{O}$ microcrystal with edge length $2.5 \mu \mathrm{m}$. The low-magnification micrograph in Fig. 5(b) shows a few of the truncated octahedra on the HOPG substrate, where the $\{100\}$ faces 
can still be seen on them. In addition to the octahedral shape, some other interesting configurations were also deposited on the substrate. Fig. 6(a-e) show different transient structures found over this region of the substrate at 300s of deposition time at $80 \mathrm{mV}$. Fig 6(a) shows a four-leaf flower structure with four identical leaves pointing outward along two orthogonal $\langle 100\rangle$ directions and a stamen in the middle, which points upward along the $\langle 100\rangle$ direction. Fig. 6(b) shows a similar flower structure but with four stamens in the middle. Fig. 6(c) shows a dendritic structure comprising four dendritic leaves along the orthogonal $\langle 100\rangle$ directions. Fig. 6(d) shows three butterfly-like structures with two wings on either side and the main body pointing towards a $\langle 100\rangle$ direction. Fig. 6(e) shows an incomplete octahedron showing the gaps in between and the incomplete faces. It is possible that they are the transient structures during the growth towards eventually a full octahedron.

Fig. 7(a,b) show a TEM bright-field image, high-resolution lattice image and the corresponding SAED pattern taken along the [001] zone of a leaf from the $\mathrm{Cu}_{2} \mathrm{O}$ flower-structured microcrystal desquamated from a HOPG electrode. The $\{110\}$ planes are labeled in the high-resolution image and the corresponding reflections are indicated in the diffraction pattern. The SAED shows a cubic crystal structure with interplanar spacing in agreement with the lattice constant of $0.427 \mathrm{~nm}$ of $\mathrm{Cu}_{2} \mathrm{O}$. Again, no grain boundary or changes in the crystal orientation could be detected and so it was confirmed to be a single crystal. Fig. 8 shows another TEM bright-field image and the corresponding SAED pattern taken along the $[1 \overline{1} 0]$ zone of a truncated octahedral 
microcrystal desquamated from the HOPG. From the determined orientation of the crystal, the direction joining the two twin apexes was along the $\langle 100\rangle$ direction. The measured lattice constant also agrees with that of $\mathrm{Cu}_{2} \mathrm{O}$.

Microstructures such as those in Figs. 6(b-d) which appear to be composed of several smaller crystals were further analyzed by EBSD. Fig 9(a) shows the SEM micrograph of such a microstructure, and the corresponding EBSD map is shown in Fig. 9(b). As can be seen from Fig. 9(a), the $\mathrm{Cu}_{2} \mathrm{O}$ flower-like microstructure appears to consist of five crystals with four leaves and one stamina in the middle, but the EBSD map with Euler angles in Fig. 9(b) shows that all five composing crystals have identical orientation. This supports that the leaves and stamina are parts of one single crystal with no grain boundaries inside. Backscattered Kikuchi pattern of different microcrystals at different points further confirms that the deposited material is $\mathrm{Cu}_{2} \mathrm{O}$. Fig. $10(a, b)$ are the SEM images of typical dendrite and the butterfly-like structures while $10(\mathrm{c}, \mathrm{d})$ are the corresponding Kikuchi patterns. Again, the Kikuchi patterns are confirmed to be consistent with that of $\mathrm{Cu}_{2} \mathrm{O}$. Chemical compositions of the microstructures were also determined by EDX, as shown in Fig. 11. Only $\mathrm{Cu}$ and $\mathrm{O}$ were detected, confirming that the microcrystals were copper oxide.

\section{2. $\mathrm{Cu}_{2} \mathrm{O}$ deposition on $\mathrm{Cu}$ anode}

Besides the HOPG cathode, the $\mathrm{Cu}$ anode was also examined after the 
electrodeposition experiments. Fig. 12 shows an SEM image of the surface of the $\mathrm{Cu}$ anode after electrodeposition on HOPG at $80 \mathrm{mV}$ for 300 s. The surface of the $\mathrm{Cu}$ anode was covered by nanocrystals of generally octahedral shapes ranging from several tens of $\mathrm{nm}$ to $1 \mu \mathrm{m}$. Fig. 13(a, b) shows a TEM bright-field image and the corresponding SAED pattern of the crystals desquamated from the $\mathrm{Cu}$ anode. The SAED pattern is identified to be a simple cubic structure with lattice constant of 0.42 $\pm 0.01 \mathrm{~nm}$, which is again in agreement with the $\mathrm{Cu}_{2} \mathrm{O}$ structure.

\section{Discussion}

In the present experiments, the micro/nanowires were all found deposited on the step edges of the HOPG substrates instead of the terraces, suggesting that step edges offer a lower nucleation barrier than terraces, in accordance with the common belief that nuclei are more readily formed on the step edges thus causing the high degree of selectivity during electrodeposition $[15,26]$. Thus, nucleation may first occur on the HOPG steps to form discrete nanocrystals. After some time, the crystals grow and subsequently coalesce into a continuous nanowire. As in Fig. 1(c), the nanowire is polycrystalline comprising many single crystals with different orientations arranged in series along the step edge.

Unlike those studies in the literature where nanowires on HOPG were obtained by three potentiostatic pulses during electrodeposition, which include the oxidizing 
“activation" pulse, a reducing "nucleation" pulse and a reducing "growth" pulse [17, 22], we managed to synchronize the nucleation and growth processes to fabricate both $\mathrm{Cu}_{2} \mathrm{O}$ nano/micro wires as well as single crystals on HOPG by one-step, low-potential electrodeposition at room temperature $\left(25^{\circ} \mathrm{C}\right)$ without the use of any additives. Furthermore, as discussed in section 3.1.3, the product at the anode, not just the cathode, was also $\mathrm{Cu}_{2} \mathrm{O}$. The possible chemical reactions at the cathode are as follow:

$2 \mathrm{Cu}^{2+}+\mathrm{H}_{2} \mathrm{O}+2 \mathrm{e}^{-} \rightarrow \mathrm{Cu}_{2} \mathrm{O}+2 \mathrm{H}^{+}$

The standard electrode potential versus standard hydrogen electrode (SHE) of the above reaction is $0.203 \mathrm{~V}$. According to the calculation using the Nernst equation by Yu et al [27], the equilibrium electrode potential of this reaction is relatively high. Therefore, formation of $\mathrm{Cu}_{2} \mathrm{O}$ is thermodynamically favourable in this case and $\mathrm{Cu}_{2} \mathrm{O}$ is deposited in priority. During electrodeposition, $\mathrm{Cu}^{2+}$ ions from the electrolyte were driven by electric field to the cathode. Because of the low potential, $\mathrm{Cu}^{2+}$ ions are slowly attracted to the surface and reduced to form a smooth surface with lowest specific energy.

For anode, the possible chemical reactions are:

$$
\begin{aligned}
& \mathrm{Cu}+2 \mathrm{OH}^{-} \rightarrow \mathrm{Cu}(\mathrm{OH})_{2}^{-}+\mathrm{e}^{-} \\
& 2 \mathrm{Cu}(\mathrm{OH})_{2}^{-} \rightarrow \mathrm{Cu}_{2} \mathrm{O}+\mathrm{H}_{2} \mathrm{O}+2 \mathrm{OH}^{-} \\
& 2 \mathrm{Cu}+2 \mathrm{OH}^{-} \rightarrow \mathrm{Cu}_{2} \mathrm{O}+\mathrm{H}_{2} \mathrm{O}+2 \mathrm{e}^{-} \quad \text { (overall reaction) }
\end{aligned}
$$


During electrodeposition, $\mathrm{Cu}$ from the anode copper plate oxidizes to form $\mathrm{Cu}^{+}$ions. They were stabilized immediately by $\mathrm{OH}^{-}$ions to form $\mathrm{Cu}(\mathrm{OH})_{2}^{-}$, which would then decompose to form $\mathrm{Cu}_{2} \mathrm{O}$. Therefore, formation of $\mathrm{Cu}_{2} \mathrm{O}$ is favorable and no $\mathrm{CuO}$ is formed at the anode. [28]

Compared with the experiment by Xiao et al. [22] where they used three potentiostatic pulses with a long deposition time (50min) to obtain nanowires with length over $250 \mu \mathrm{m}$, we demonstrated a more effective method by using just one single electrodeposition step at a low voltage with a short deposition time (60s). The as-deposited nanowires in our experiments are highly uniform and continuous up to $100 \mu \mathrm{m}$. Besides the long and continuous nanowires, some discrete nanowires were also observed on the HOPG. These were short and discontinuous, and this is possibly due to the Interparticle Diffusion Coupling (IDC) effect [21]. The growth of each deposited nucleus is influenced by the concentration of the ions around it and the position of the crystal grain. During electrodeposition, each nucleus has its own depleting zone but since some of the nuclei are deposited more closely together than others, their depleting zones will overlap. Fewer ions are around the overlapped depleting zone and so electrodeposition is not favored there causing the IDC effect. Under this condition, the deposited nanowires become discrete and discontinuous.

On the other hand, the morphology of the nanowires in our experiments is different from that reported by Zach et al. [26], who investigated the synthesis of 
molybdenum nanowires by electrochemical step edge decoration. In Zach et al's study, the morphology of the nanowires changed from discrete, beaded and discontinuous to smooth, cylindrical and continuous when the deposition time increased from 8 s to $256 \mathrm{~s}$ at $0.95 \mathrm{~V}$. In the present study, however, when the deposition time was increased from $60 \mathrm{~s}$ to $300 \mathrm{~s}$ at $80 \mathrm{mV}$, the nanowires did not change to smooth and cylindrical nanowires, but instead, each of the comprising crystals grew in size and remained as an octahedron. The result is the formation of a beaded continuous wire but with diameter increased to the micron regime as in Fig. 3(b).

Despite the fact that various configurations of $\mathrm{Cu}_{2} \mathrm{O}$ crystals have been synthesized in the literature, for example, cubic, six-horn, eight-pod, triangular pyramidal, and icositetrahedron [29-32], these were synthesized by other processes or by adjusting the $\mathrm{pH}$ value of the electrolyte. In this study, we managed to fabricate $\mathrm{Cu}_{2} \mathrm{O}$ crystals of different configurations on HOPG by electrodeposition, and in particular, $\mathrm{Cu}_{2} \mathrm{O}$ crystals with dendrite and butterfly-like structures are produced for the first time. $\mathrm{Cu}_{2} \mathrm{O}$ crystals were also found on the $\mathrm{Cu}$ anode which suggests that $\mathrm{Cu}_{2} \mathrm{O}$ crystals can be prepared also by anodic deposition, i.e. $\mathrm{Cu}_{2} \mathrm{O}$ crystals can be fabricated on both electrodes in a single step. We have recently demonstrated that, under similar conditions but with different potentials, uniform nano-to-micron sized $\mathrm{Cu}_{2} \mathrm{O}$ crystals can be fabricated on $\mathrm{Si}$ wafer and stainless steel substrate as well [28]. 


\section{Conclusions}

We successfully fabricated one- and two-dimensional $\mathrm{Cu}_{2} \mathrm{O}$ nano/microstructures on HOPG by one-step, low-potential electrodeposition in a simple two-electrode setup at room temperature $\left(25^{\circ} \mathrm{C}\right)$ with no additives. Highly aligned nano/microwires were found deposited on the step edges of the HOPG. They were "beaded" polycrystalline nano/microwires comprising octahedral crystals of different orientations. The as-deposited $\mathrm{Cu}_{2} \mathrm{O}$ nanowires with diameters ranging from $100 \mathrm{~nm}$ to $300 \mathrm{~nm}$ were highly uniform and continuous and more than $100 \mu \mathrm{m}$ long, while the microwires with diameters ranging from $1 \mu \mathrm{m}$ to $3 \mu \mathrm{m}$ had lengths up to $60 \mu \mathrm{m}$. Due to the IDC effect, some short, discrete nano/microwires were also observed during the experiments. The nanocrystals found on the terraces were of sizes ranging from 50 to $400 \mathrm{~nm}$, whereas the sizes of the microcrystals deposited ranged from $1 \mu \mathrm{m}$ to $6 \mu \mathrm{m}$. Various morphologies of microcrystals were observed on the terraces of the HOPG substrates, including full and truncated octahedra, dendrites, and butterfly-like and flower-like structures. Some of the structures are revealed for the first time by one-step electrodeposition. The steady-state shape of the nano/microcrystals seems to be octahedral with eight $\{111\}$ faces which suggests that $\{111\}$ are the most stable crystallographic planes in $\mathrm{Cu}_{2} \mathrm{O} \cdot \mathrm{Cu}_{2} \mathrm{O}$ single crystals were also found to deposit on the $\mathrm{Cu}$ anode and hence this work provides a method to fabricate $\mathrm{Cu}_{2} \mathrm{O}$ crystals on both anode and cathode in a single step. 


\section{Acknowledgements}

The work described in this paper was supported by funding from the University Grants Committee (Project No. SEG-HKU06) of the Hong Kong Special Administration Region, as well as the Kingboard Endowed Professorship. Technical assistance from Frankie Chan of the Electron Microscope Unit of the University of Hong Kong is gratefully acknowledged. 


\section{References}

[1] J. Ghijsen, L.H. Tjeng, J. van Elp, H. Eskes, Electronic structure of $\mathrm{Cu} 2 \mathrm{O}$ and CuO, Phys. Rev. B 38 (1988) 11322.

[2] P. E. de Jongh, D. Vanmaekelbergh, J.J. Kelly, Cu2O: a catalyst for the photochemical decomposition of water, Chem. Commun. (1999) 1069.

[3] J. Ramirez-Ortiz, T. Ogura, J. Medina-Valtierra, S.E. Acosta-Ortiz, P. Bosch, J.A.d.l. Reyes, V.H. Lara, A catalytic application of $\mathrm{Cu} 2 \mathrm{O}$ and $\mathrm{CuO}$ films deposited over fiberglass, Appl. Surf. Sci., 174 (2001) 177.

[4] Y. Chang, J. J. Teo, H.C. Zeng, Formation of Colloidal CuO nanocrystallites and their spherical aggregation and reductive transformation to hollow $\mathrm{Cu} 2 \mathrm{O}$ nanospheres, Langmuir 21 (2005) 1074.

[5] P.E. de Jough, D. Vanmaekelbergh, J.J. Kelly, Photoelectrochemistry of Electrodeposited Cu2O, J. Electrochem. Soc., 147 (2000) 486.

[6] J. Zhang, J. Liu, Q. Peng, X. Wang, Y. Li, Nearly Monodisperse Cu2O and CuO nanospheres: preparation and applications for sensitive gas sensors, Chem. Mater. 18 
(2006) 867.

[7] J.A. Switzer, B.M. Maune, E.R. Raub, Negative differential resistance in electrochemically self-assembled layered nanostructures, J. Phys. Chem. B 103 (1999) 395.

[8] P. Poizot, S. Laruelle, S. Grugeon, L. Dupont, J.-M. Tarascon, Nano-sized transition-metal oxides as negative-electrode materials for lithium-ion batteries, Nature, 407 (2000) 496.

[9] P. Taneja, R. Chandra, R. banerjee, P. Ayyub, Structure and properties of nanocrystalline $\mathrm{Ag}$ and $\mathrm{Cu} 2 \mathrm{O}$ synthesized by high pressure sputtering, Scripta mater. $44(2001) 1915$.

[10] L. Gou, C.J. Murphy, Solution-Phase synthesis of $\mathrm{Cu} 2 \mathrm{O}$ nanocubes, Nano Lett. 3 (2003) 231.

[11] J. Park, J. Joo, Y. Jang, T. Hyeon, Synthesis and catalytic applications of uniform-sized nanocrystals, Stud. in Surf. Sci. and Catal. 159 (2006) 47.

[12] F. Xiao, C. Hangarter, B. Yoo, Y. Rheem, K.-H. Lee, N.V. Myung, Recent progress in electrodeposition of thermoelectric thin films and nanostructures, 
Electrochim. Acta, 53 (2008) 8103.

[13] U. Erb, Electrodeposited nanocrystals: Synthesis, properties and industrial applications, Nanostruct. Mater., 6 (1995) 533.

[14] R. M. Penner, Electrochemical Step Edge Decoration (ESED): A Versatile Tool for the Nanofabrication of Wires, Modern Aspects of electrochemistry, Springer New York, 45 (2009) 175.

[15] M. P. Zach, K.H. Ng, R. M. Penner, Molydenum nanowires by electrodeposition, Science 290 (2000) 2120.

[16] I. Mukhopadhyay, W. Freyland, Electrodeposition of Ti nanowires on highly oriented pyrolytic graphite from an ionic liquid at room temperature, Langmuir 19 (2003) 1951.

[17] E.C. Walter, B.J. Murray, F. Favier, G. Kaltenpoth, M. Grunze, R. M. Penner, Noble and coinage metal nanowires by electrochemical step edge decoration, J. Phys. Chem. B 106 (2002) 11407.

[18] C. Fournier, F. Favier, Zn, Ti and Si, nanowires by electrodeposition in ionic liquid, Electrochem. Commun. 13 (2011) 1252. 
[19] Q. Li, R.M. Penner, Photoconductive cadmium sulfide hemicylindraical shell nanowire ensembles, Nano Lett., 5 (2005) 1720.

[20] E.J. Menke, Q. Li, R.M. Penner, Bismuth Telluride (Bi2Te3) nanowires synthesized by cyclic electrodeposition/stripping coupled with step edge decoration, Nano Lett., 4 (2004) 2009.

[21] L. Tang, G. Yu, Y. Ouyang, W. Si, B. Weng, Single pulse deposition of Pd-Ag alloy nanowires on highly oriented pyrolytic graphite: A mechanistic assessment, Electrochim. Acta 53 (2008) 3305.

[22]Y. Xiao, G. Yu, J. Yuan, J. Wang, Z. Chen, Fabrication of Pd-Ni alloy nanowire arrays on HOPG surface by electrodeposition, Electrochimica Acta 51 (2006) 4218.

[23] E. C. Walter, B.J. Murray, F. Favier, R.M. Penner, "beaded" bimetallic nanowires: wiring nanoparticles of metal 1 using nanowires of metal 2, Adv. Mater. 5 (2003) 396.

[24] A. P. Tomsia, A.M. Glaeser, Ceramic Microstructures, Control at the atomic level, Plenum Press, New York, (1998) 487. 
[25] R. Restori, D. Schwarzenbach, Charge density in cuprite, $\mathrm{Cu}_{2} \mathrm{O}$, Acta Crystallogr. Sect. B: Struct. Sci. 42 (1986) 201.

[26] M. P. Zach, K. Inazu, K.H. Ng, J.C. Hemminger, R. M. Penner, Synthesis of Molybdenum nanowires with millimeter-scale lengths using electrochemical step edge decoration, Chem. Mater. 14 (2002) 3206.

[27] G. Yu, X. Hu, D. Liu, D. Sun, J. Li, H. Zhang, H. Liu, J. Wang, Electrodeposition of submicron/nanoscale $\mathrm{Cu}_{2} \mathrm{O} / \mathrm{Cu}$ junctions in an ultrathin $\mathrm{CuSO}_{4}$ solution layer, $\mathrm{J}$. Electroanal. Chem. 638 (2010) 225.

[28] S. Y. Ng, A. H. W. Ngan, Fabrication of nanometer-to-micron sized $\mathrm{Cu}_{2} \mathrm{O}$ single crystals by electrodeposition, Electrochim. Acta 56 (2011) 7686.

[29] S. Xu, X. Song, C. Fan, G. Chen, W. Zhao, T. You, S. Sun, Kinetically controlled synthesis of $\mathrm{Cu}_{2} \mathrm{O}$ microcrystals with various morphologies by adjusting pH value, J. Cryst. Growth 305 (2007) 3.

[30] L. Wang, H. Jia, L. Shi, N. Liao, X. Yu, D. Jin, Controlled synthesis of $\mathrm{Cu}_{2} \mathrm{O}$ micro-crystals with various morphologies by adjusting solution conditions, Inorg. Mater. 46 (2010) 847. 
[31] S. Joseph, P.V. Kamath, Electrochemical deposition of $\mathrm{Cu}_{2} \mathrm{O}$ on stainless steel substrates: Promotion and suppression of oriented crystallization, Solid State Sci. 10 (2008) 1215.

[32] W. Zhao, W. Fu, H. Yang, C. Tian, R. Ge, C. Wang, Z. Liu, Y. Zhang, M. Li, Y. $\mathrm{Li}$, Shape-controlled synthesis of $\mathrm{Cu}_{2} \mathrm{O}$ microcrystals by electrochemical method, Appl. Surf. Sci. 256 (2010) 2269. 


\section{Figures Captions}

Fig. 1. (a) SEM image showing the distribution of $\mathrm{Cu}_{2} \mathrm{O}$ nanocrystals and nanowires electrodeposited over HOPG substrate at $80 \mathrm{mV}$ for $60 \mathrm{~s}$. (b) A single octahedral shaped $\mathrm{Cu}_{2} \mathrm{O}$ nanocrystal deposited on a HOPG substrate in high magnification. (c) SEM image showing the continuity and the shape of a $\mathrm{Cu}_{2} \mathrm{O}$ nanowire.

Fig. 2. (a) TEM bright-field image of a truncated octahedron $\mathrm{Cu}_{2} \mathrm{O}$ nanocrystal deposited on HOPG substrate. (b) Selected-area electron diffraction (SAED) pattern of the as-deposited $\mathrm{Cu}_{2} \mathrm{O}$ nanocrystal at zone [01].

Fig. 3. (a) SEM micrograph showing $\mathrm{Cu}_{2} \mathrm{O}$ microcrystals and microwires deposited at $80 \mathrm{mV}$ for $300 \mathrm{~s}$ on HOPG substrate. (b) $\mathrm{A} \mathrm{Cu}_{2} \mathrm{O}$ microwire deposited on the step edge of a HOPG substrate in high magnification.

Fig. 4. TEM bright-field image of a $\mathrm{Cu}_{2} \mathrm{O}$ microwire fragment desquamated from HOPG substrate. The top row of inset SAED patterns were taken at the same specimen tilt with the left crystal along the [110] zone. The bottom row of insets show the SAED patterns along the [001] and [110] zone of the middle and right crystal respectively. 
Fig. 5. (a) SEM image showing a typical octahedron $\mathrm{Cu}_{2} \mathrm{O}$ microcrystal deposited on HOPG substrate at $80 \mathrm{mV}$ for $300 \mathrm{~s}$. (b) Low-magnification micrograph showing a few of the incomplete octahedra on the HOPG substrate

Fig. 6. SEM images showing different transient structures of $\mathrm{Cu}_{2} \mathrm{O}$ microcrystals found over the HOPG substrate at $80 \mathrm{mV}$ for 300s: (a) a four-leaf flower structure viewed along a [100] direction, (b) a four-leaf flower structure with four stamens, (c) a dendrite comprising four dendritic leaves along the <100> directions, (d) three butterfly-like structures, (e) an incomplete octahedron showing gaps in between.

Fig. 7. (a) TEM bright-field image and (b) high-resolution lattice image of a HOPG-deposited $\mathrm{Cu}_{2} \mathrm{O}$ microcrystal taken along the [001] zone. The inset in (b) is the corresponding SAED pattern.

Fig. 8. TEM bright-field image and the corresponding SAED pattern taken along the

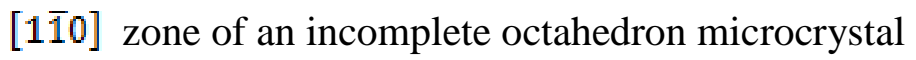

Fig. 9. SEM image (a) and EBSD orientation map (b) of a $\mathrm{Cu}_{2} \mathrm{O}$ flower-like microstructure deposited on HOPG substrate. 
Fig. 10. SEM image showing (a) a dendrite, (b) a butterfly-like microstructure analyzed by EBSD. The corresponding backscattered Kikuchi patterns of the (c) dendrite, (d) butterfly-like microstructure.

Fig. 11 EDX analysis result of an as-deposited microwire.

Fig. 12. SEM image showing the surface of the $\mathrm{Cu}$ anode after an electrodeposition experiment with HOPG cathode at $80 \mathrm{mV}$ for $300 \mathrm{~s}$. The surface is covered with a high density of octahedral shaped $\mathrm{Cu}_{2} \mathrm{O}$ crystals.

Fig. 13. (a) TEM bright-field image of $\mathrm{Cu}_{2} \mathrm{O}$ nanocrystals desquamated from $\mathrm{Cu}$ anode. (b) The corresponding SAED pattern. 


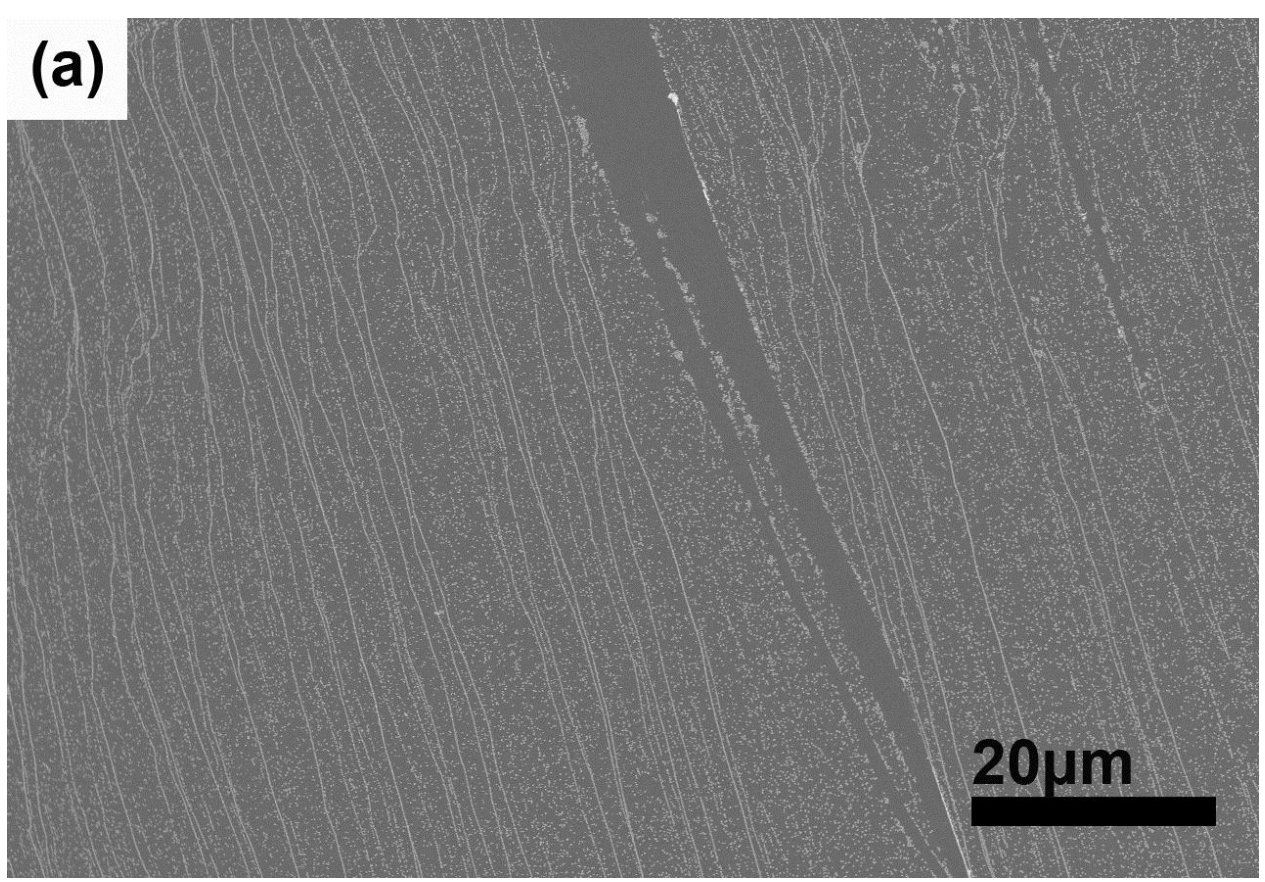

Fig. 1(a)

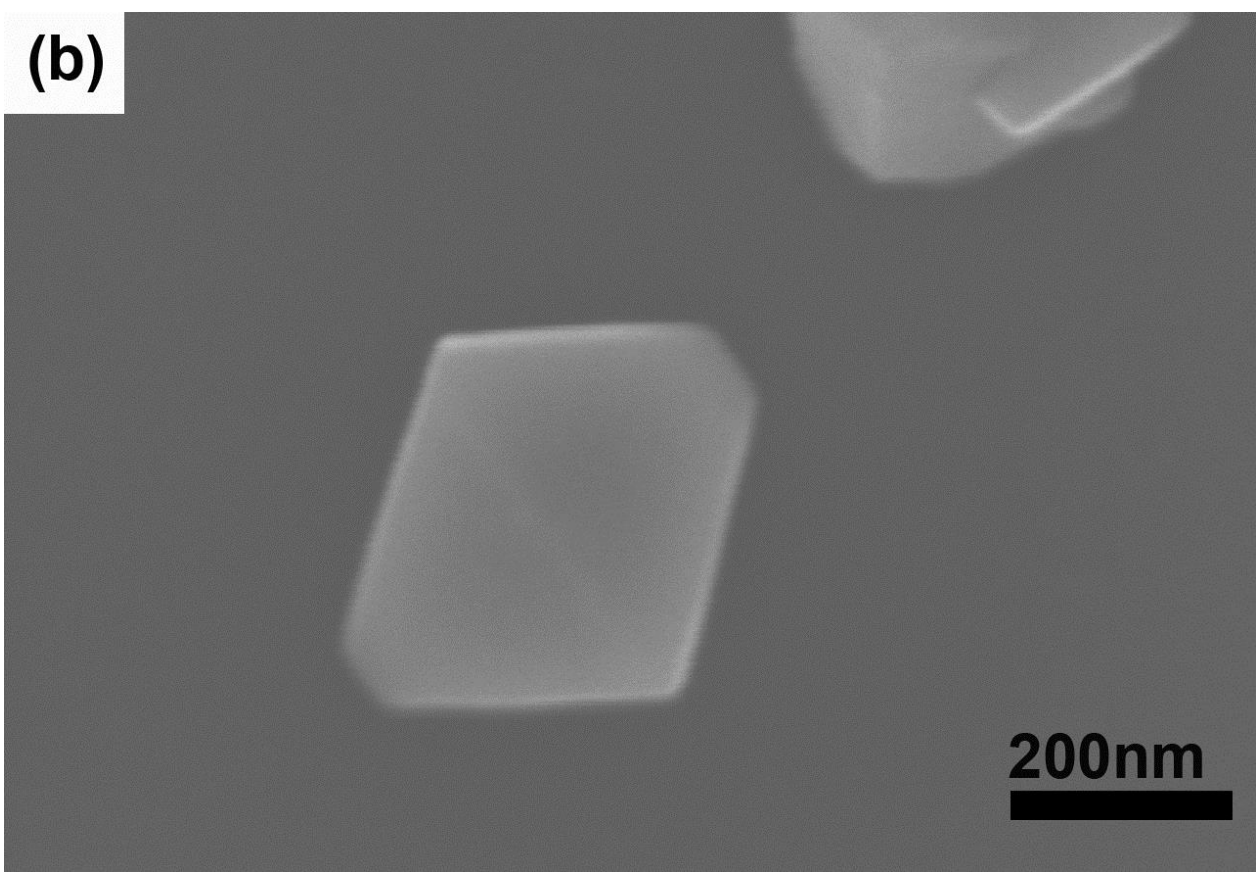

Fig. 1(b) 


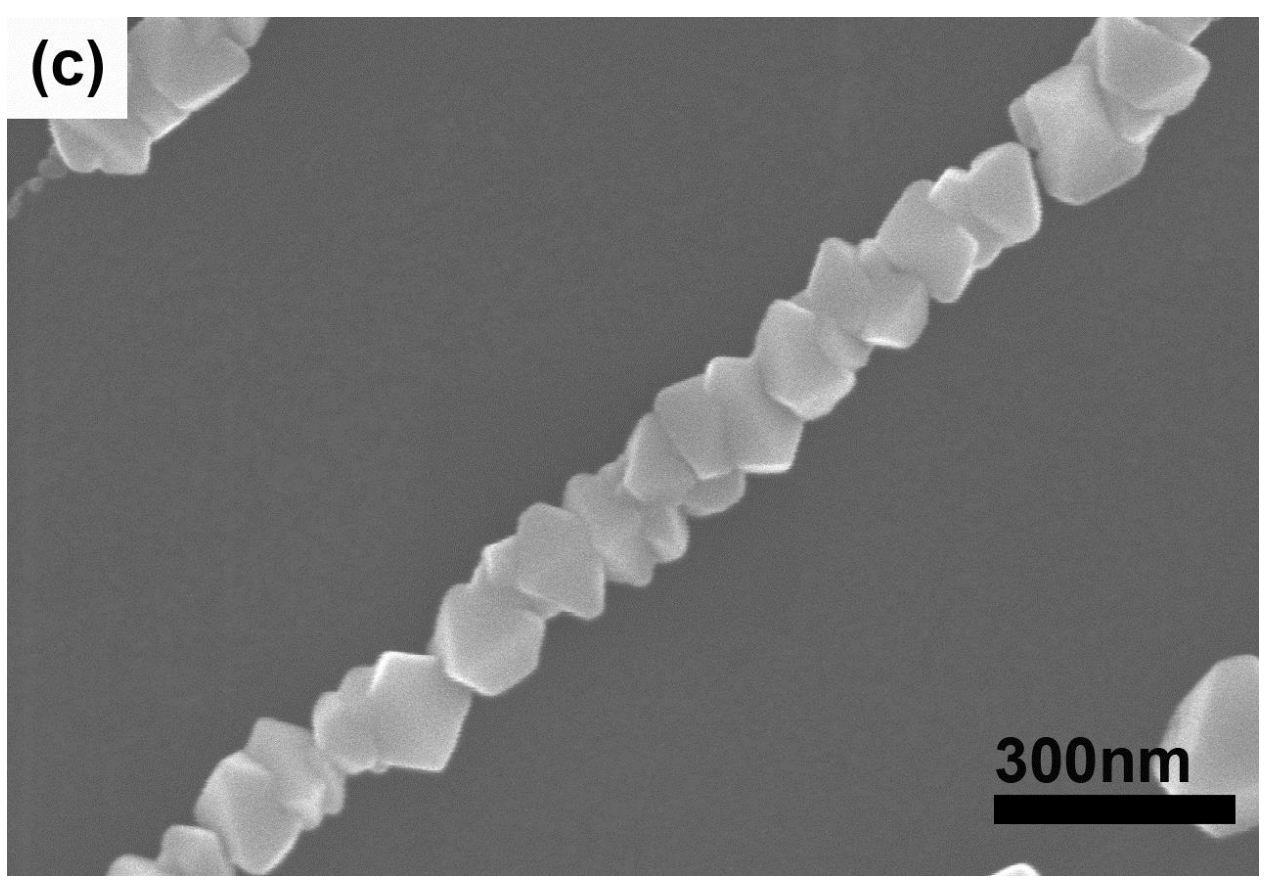

Fig. 1(c)

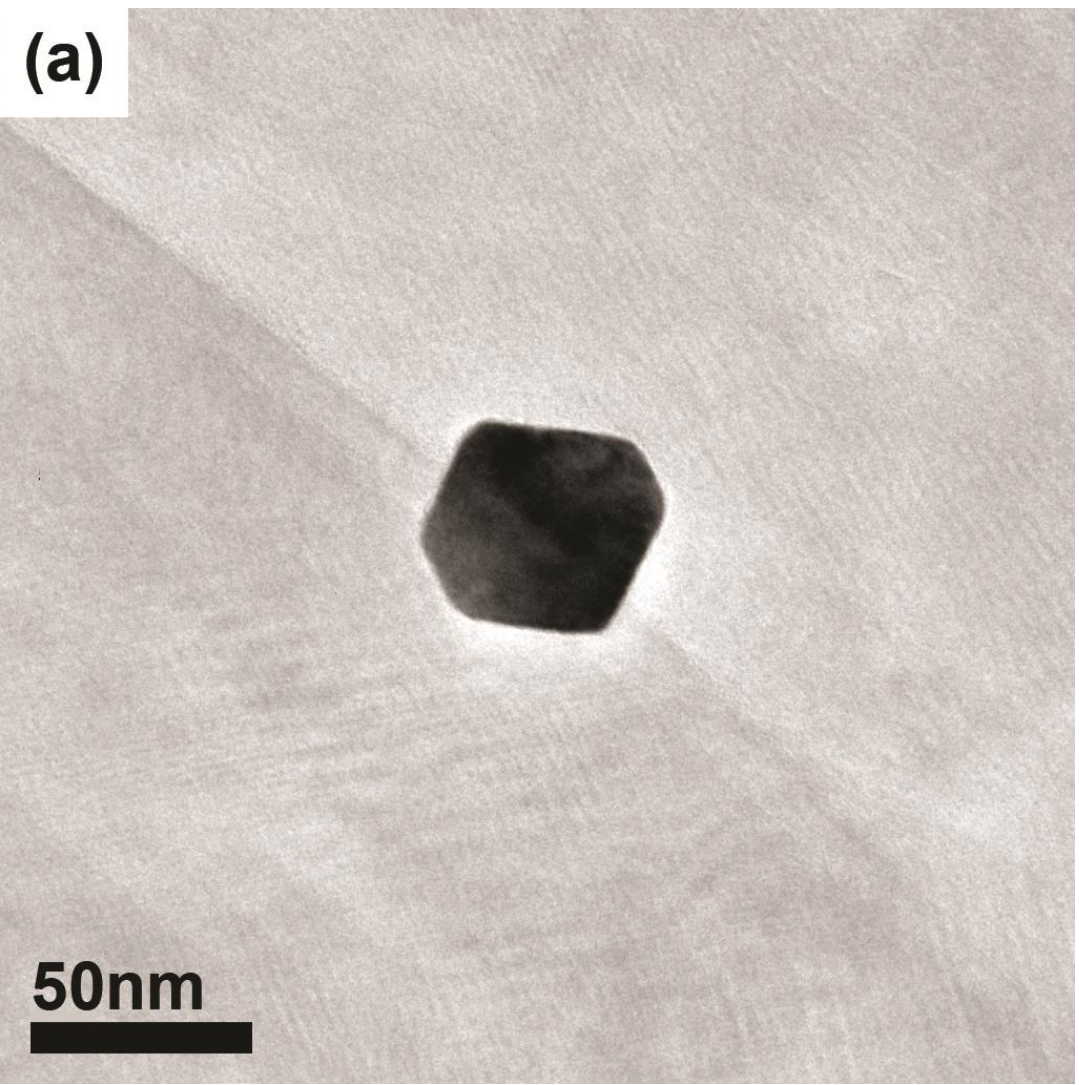

Fig. 2(a) 


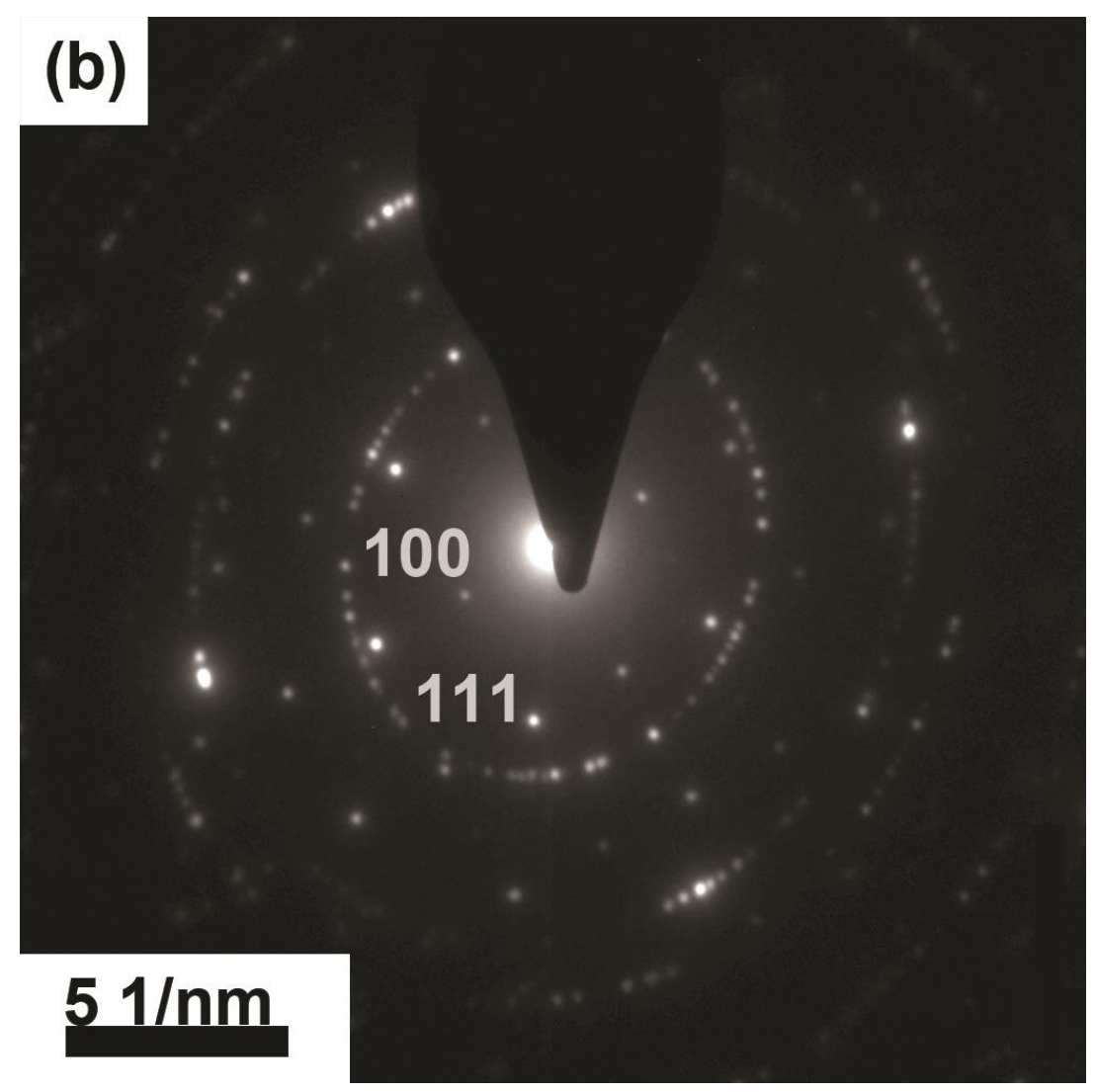

Fig. 2(b)

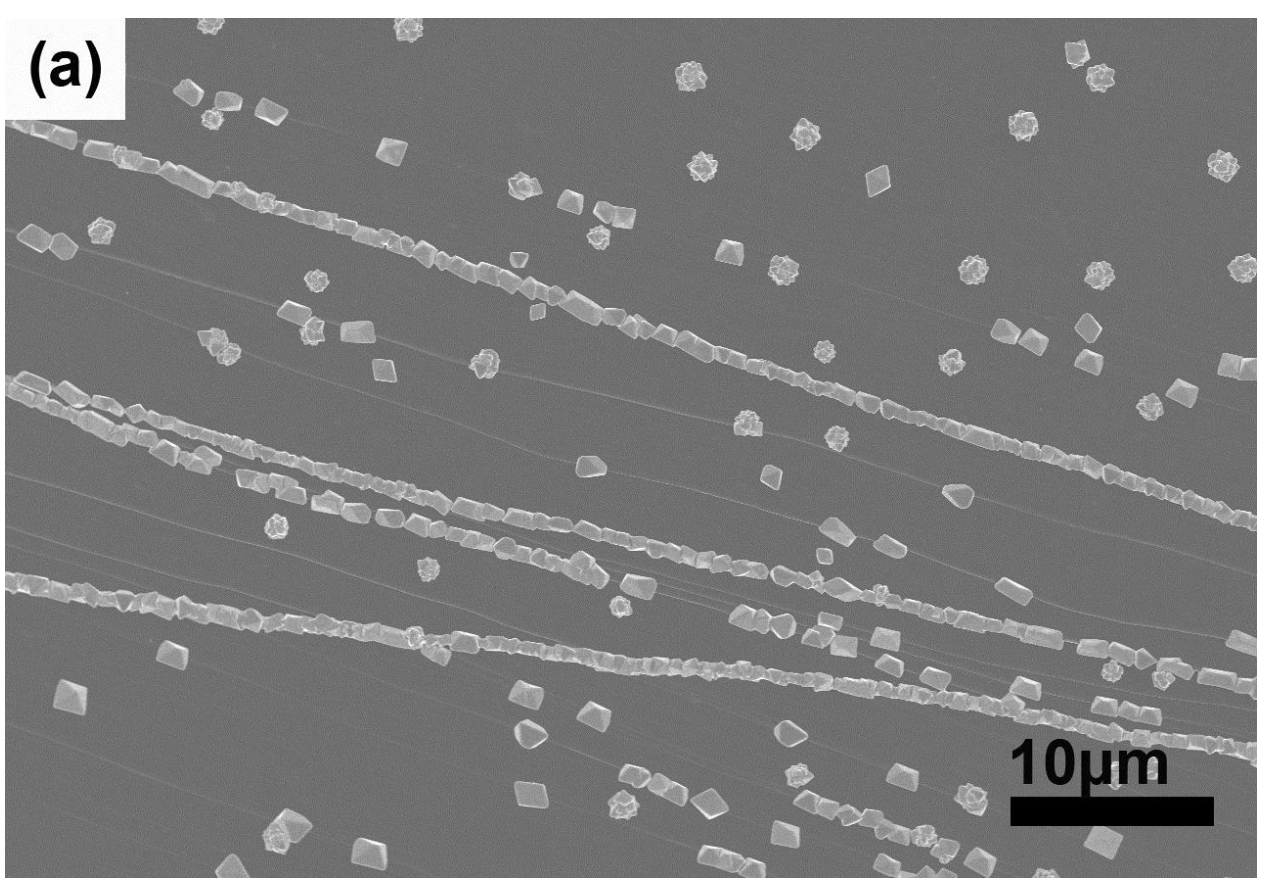

Fig. 3(a) 


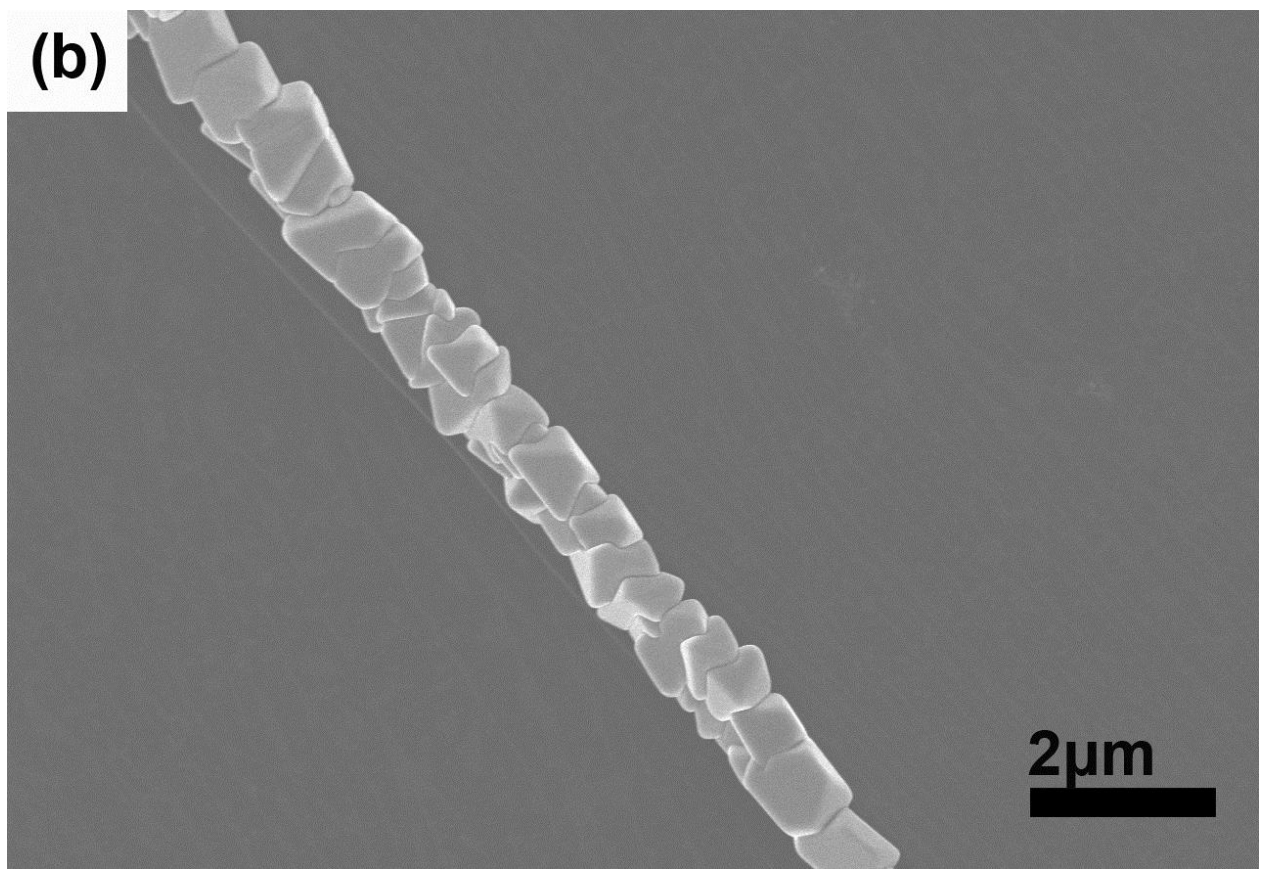

Fig. 3(b)

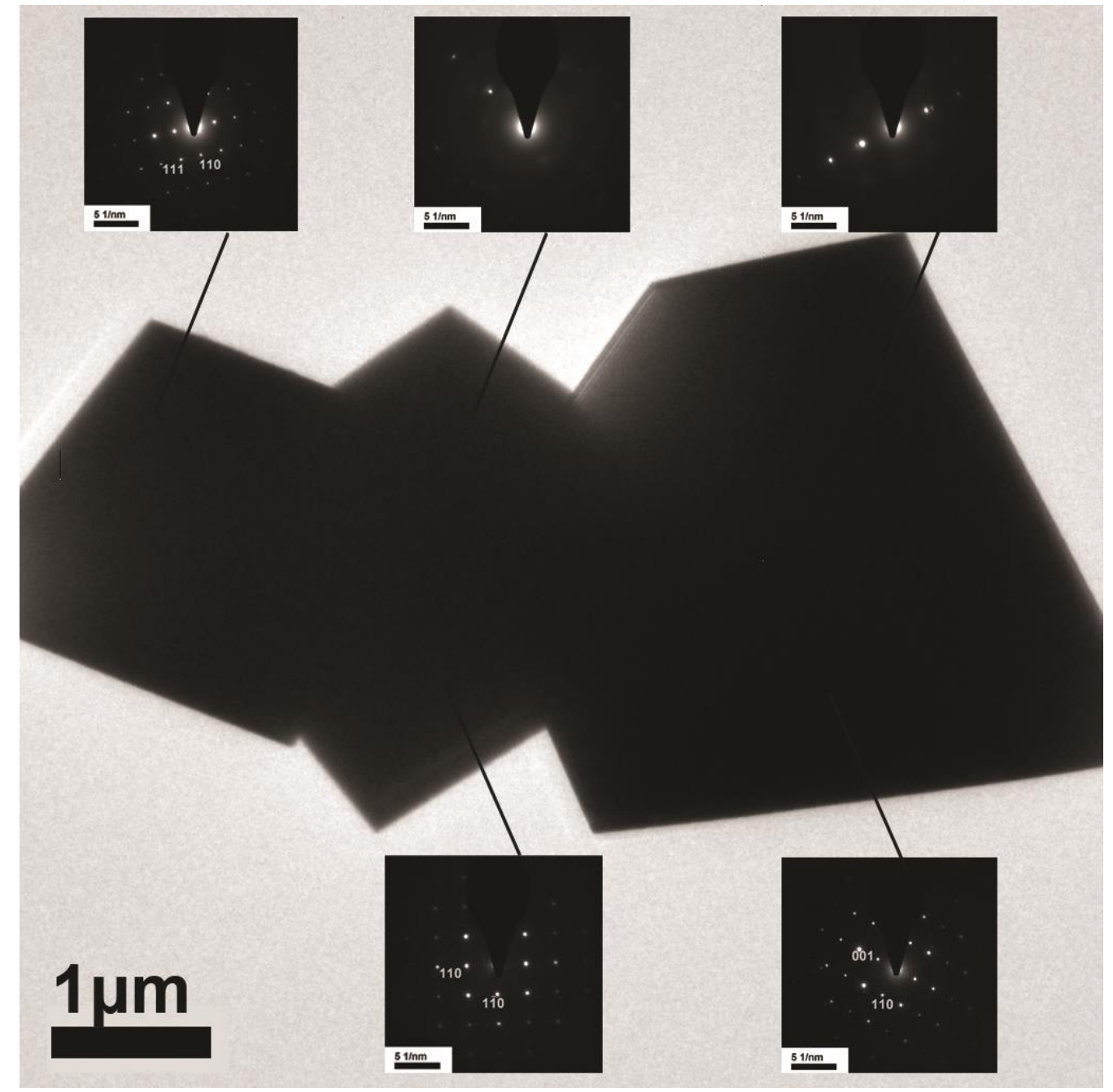

Fig. 4 
(a)

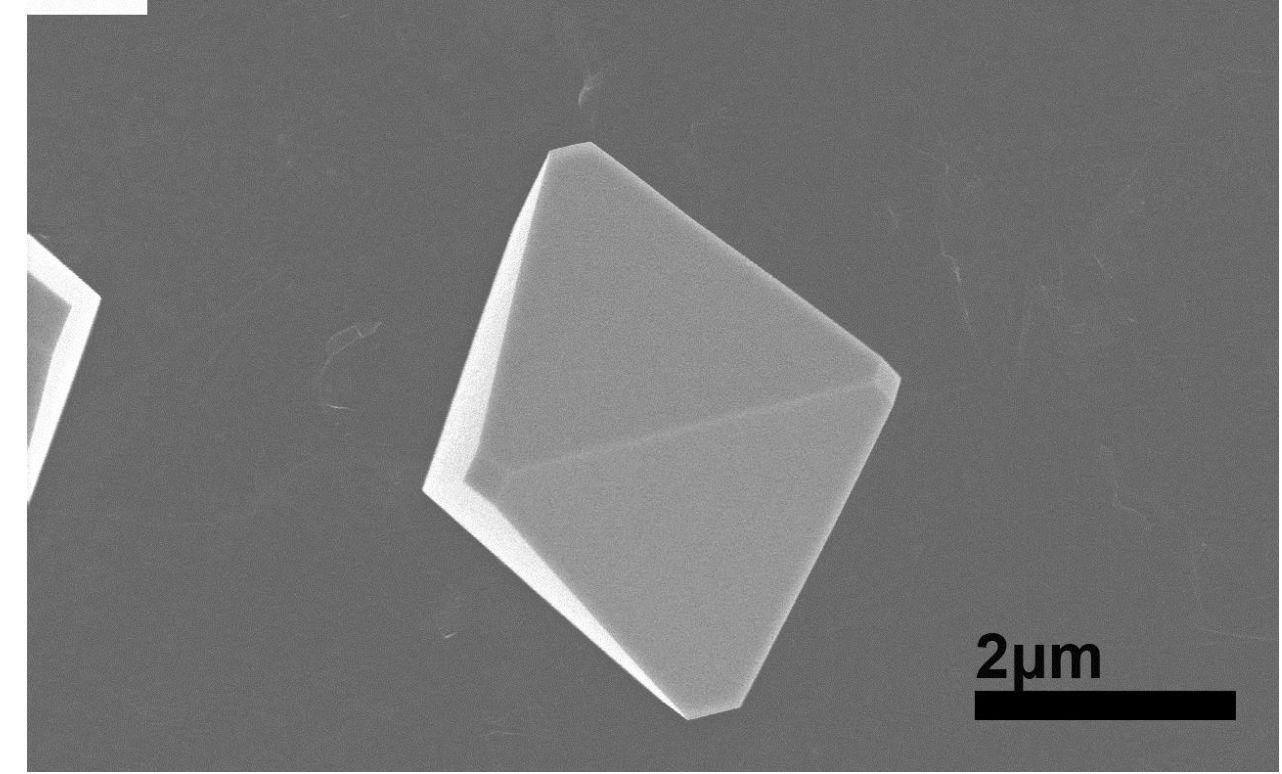

Fig. 5(a)

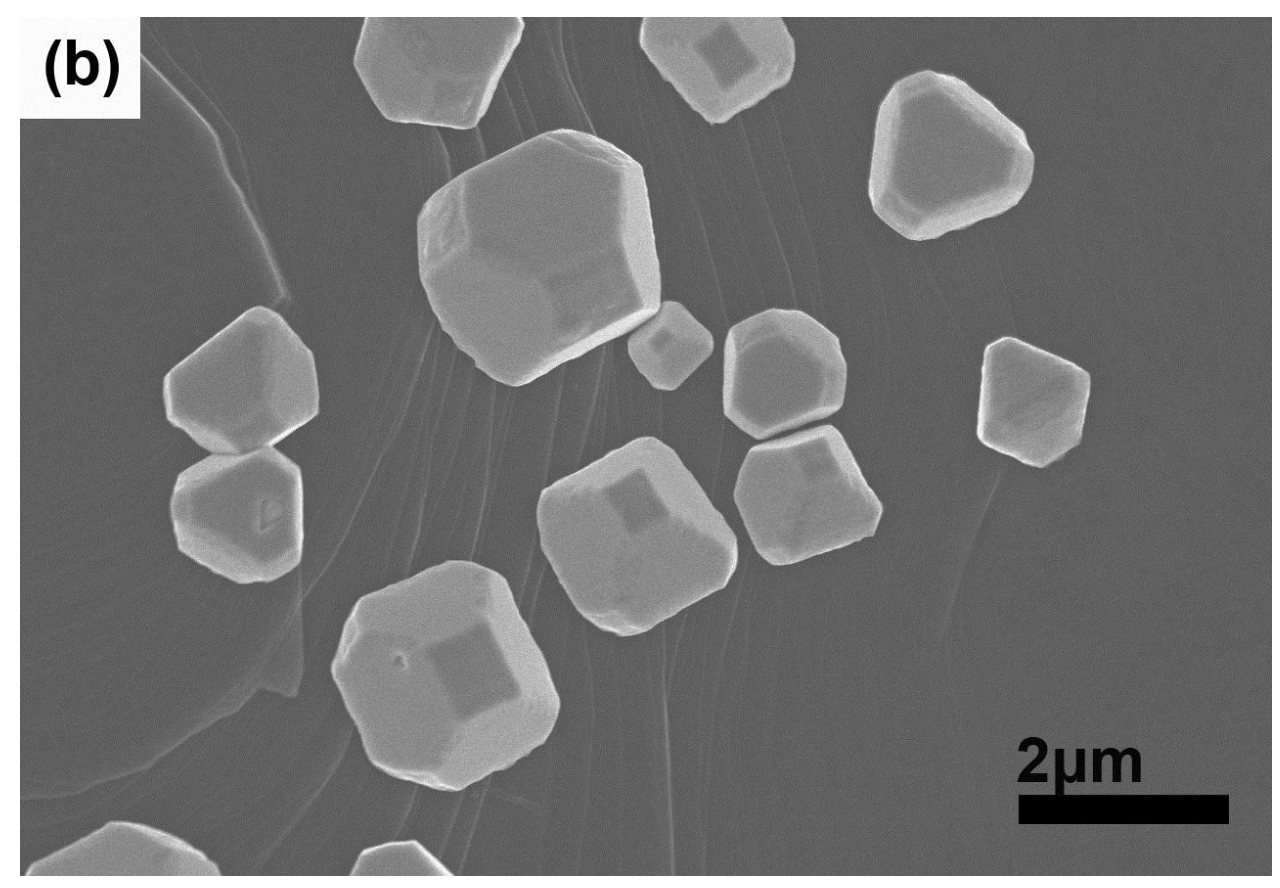

Fig. 5(b) 


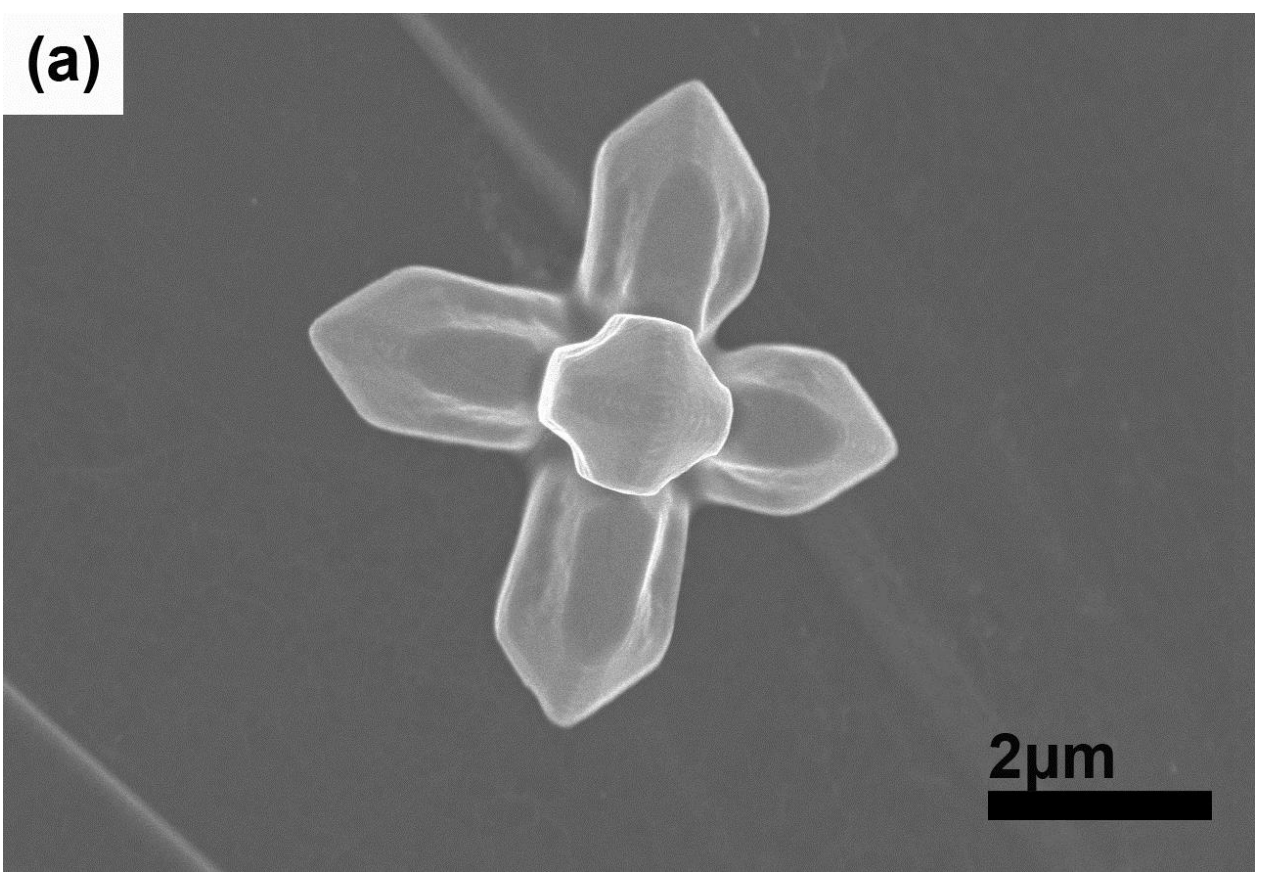

Fig. 6(a)

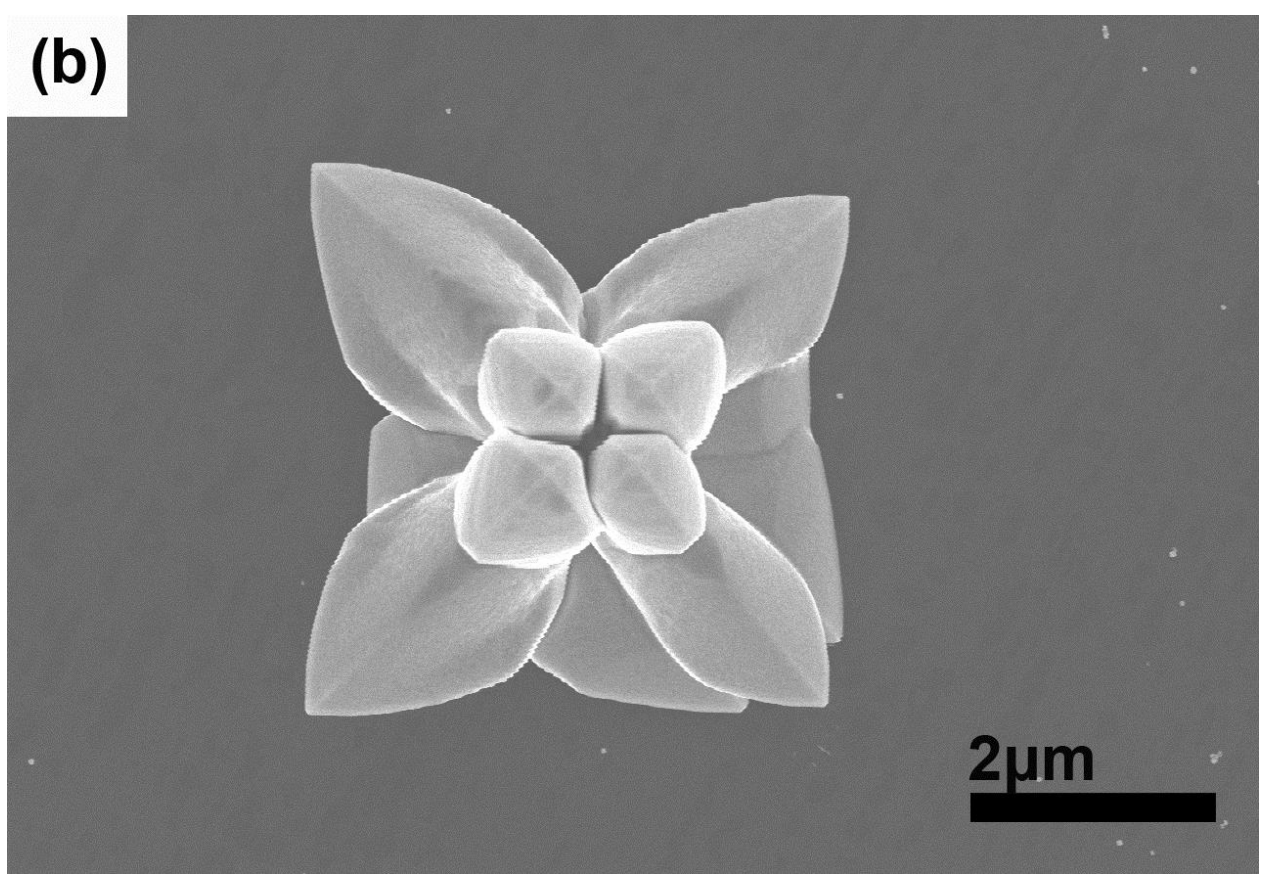

Fig. 6(b) 


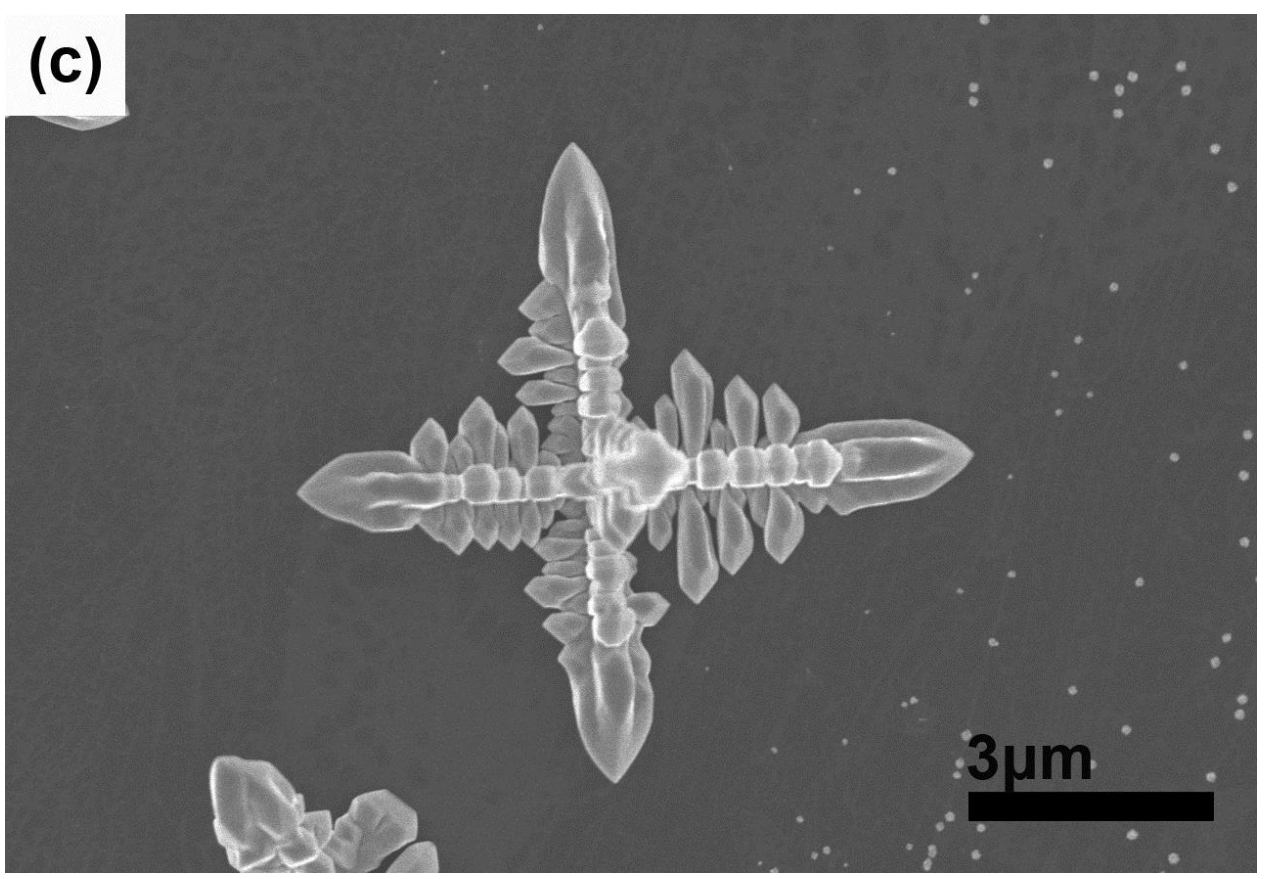

Fig. 6(c)

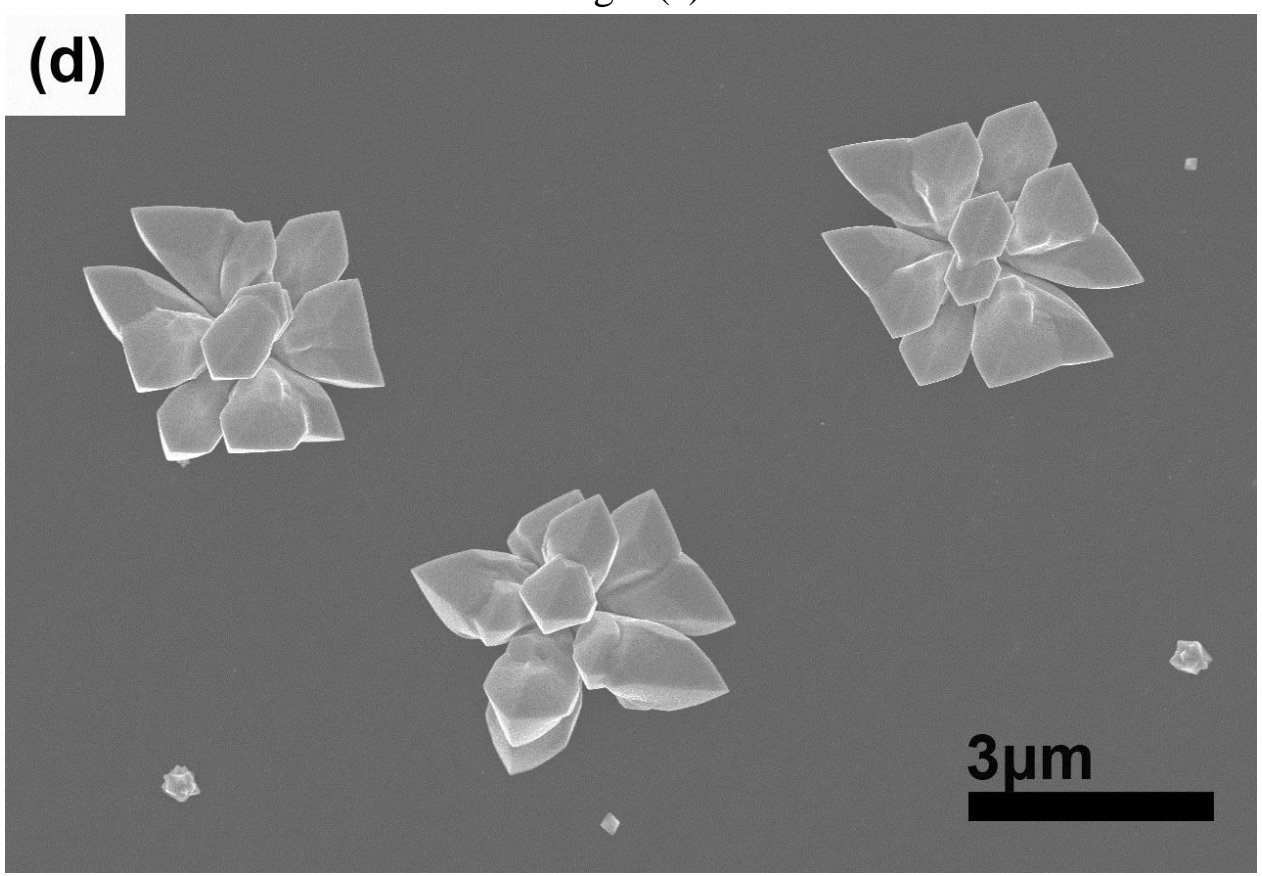

Fig. 6(d) 


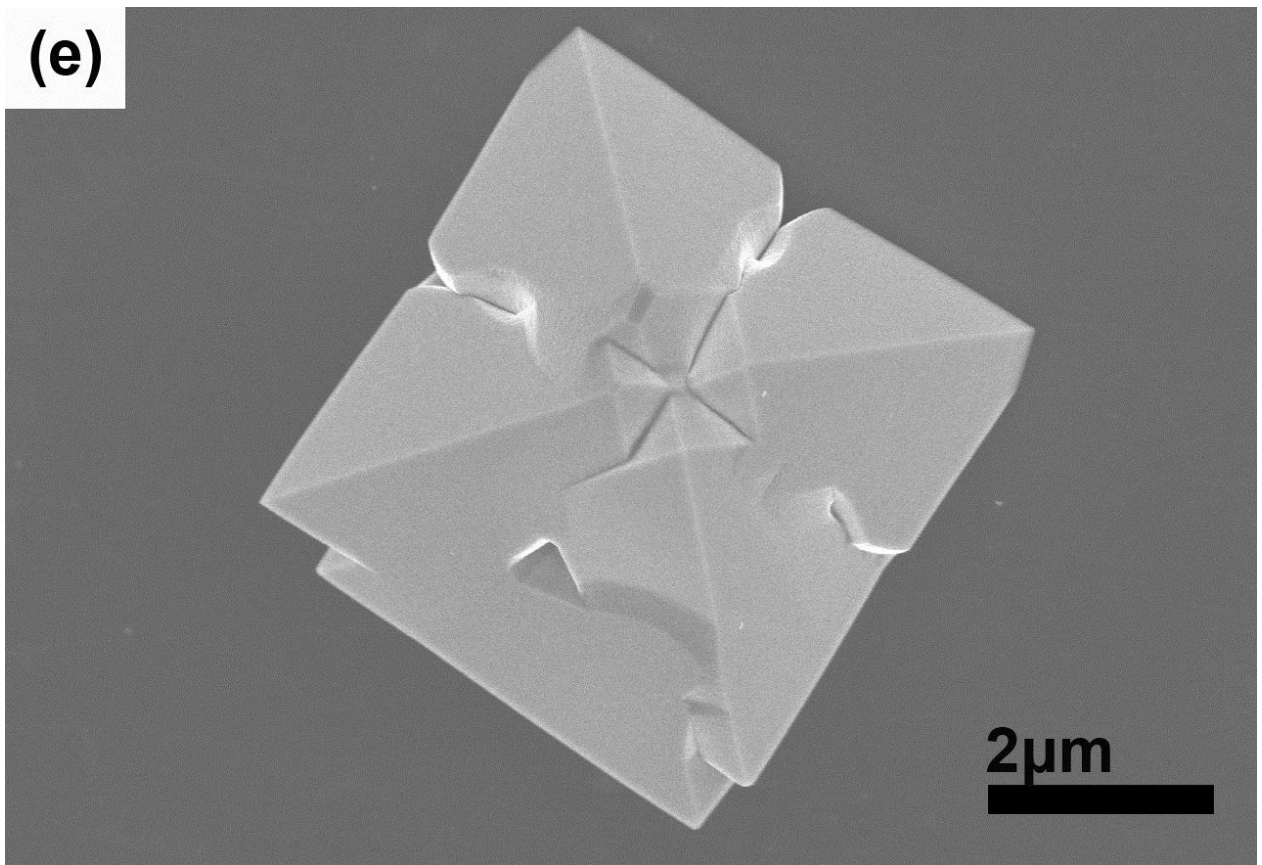

Fig. 6(e)

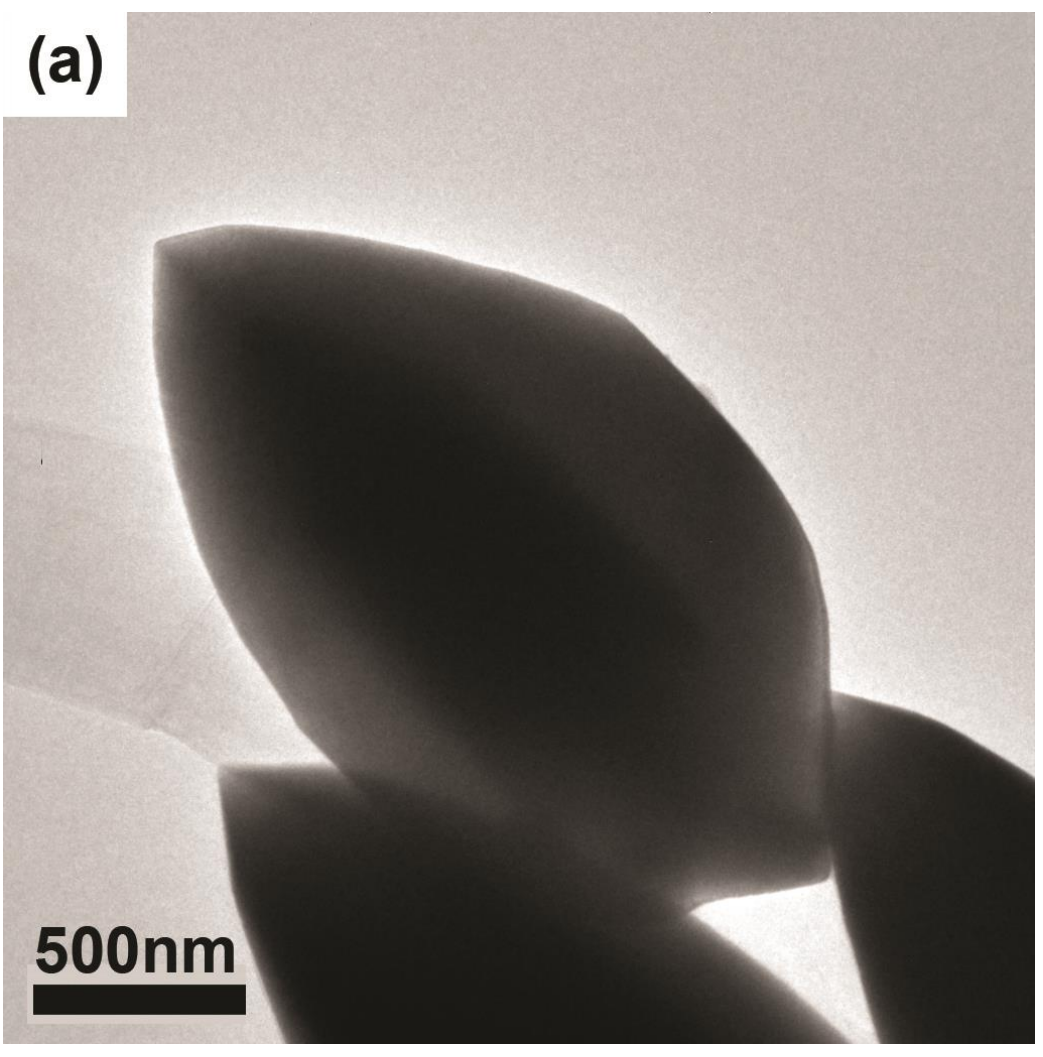

Fig. 7(a) 


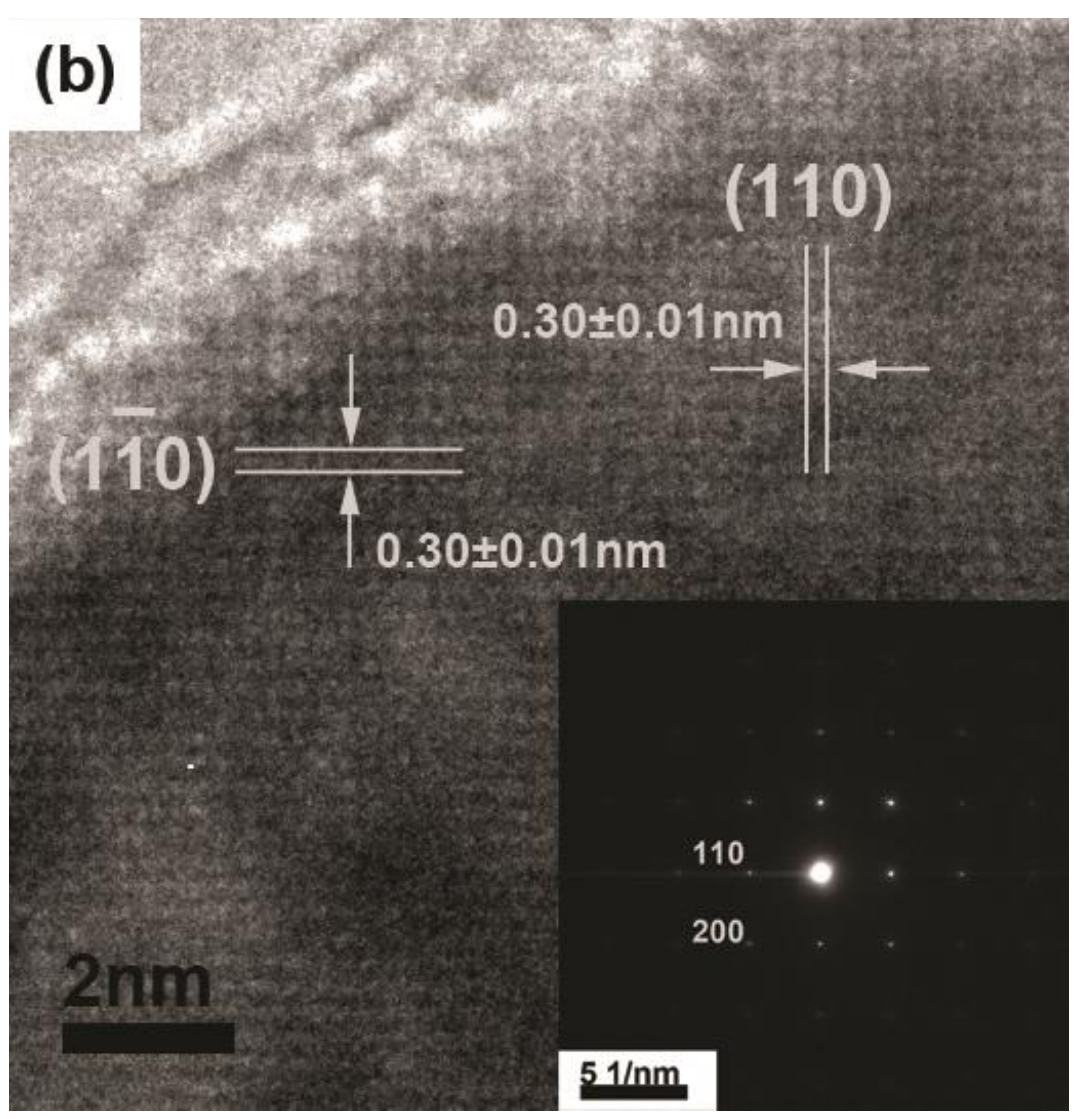

Fig. 7(b)

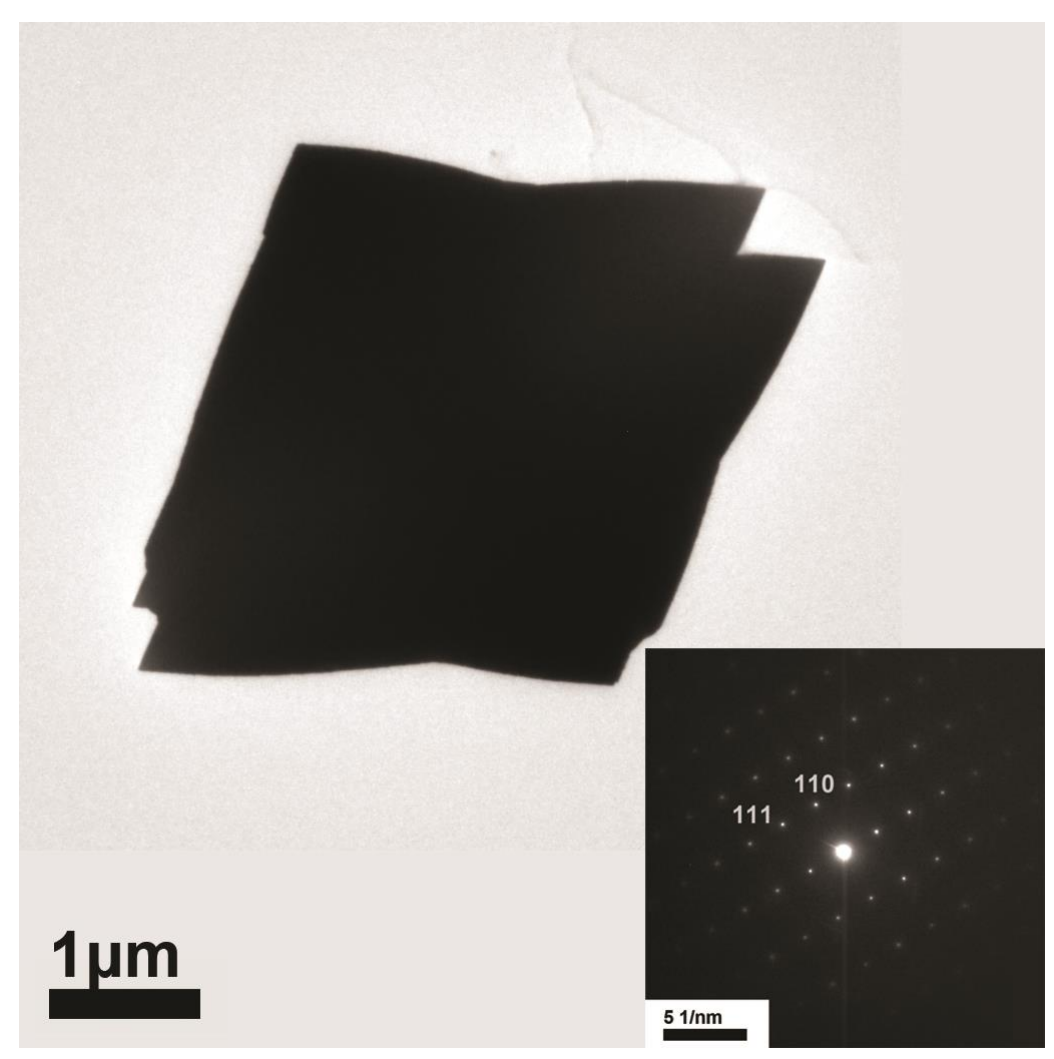

Fig. 8(a) 
(a)

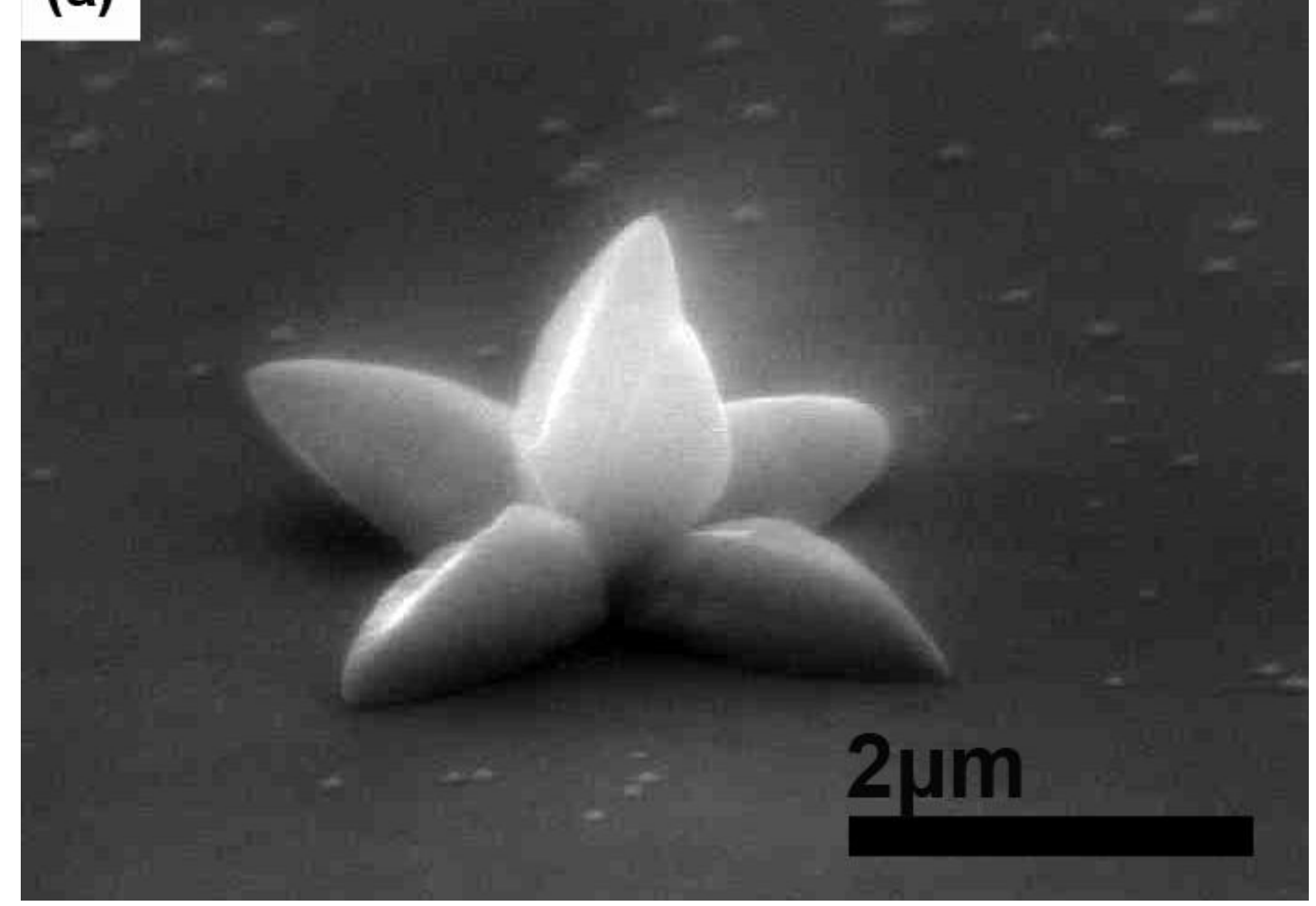

Fig. 9(a)

(b)

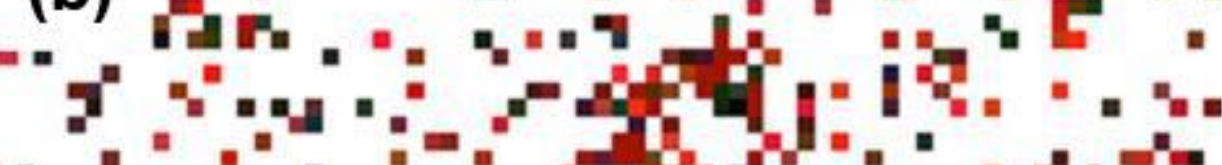
" - =

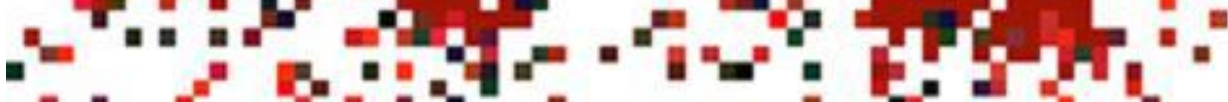
1.1." "

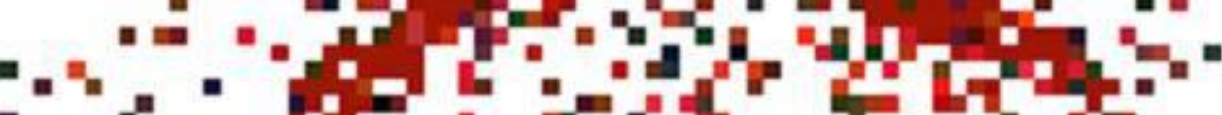
. "

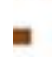
ह 14)

Fig. 9(b) 


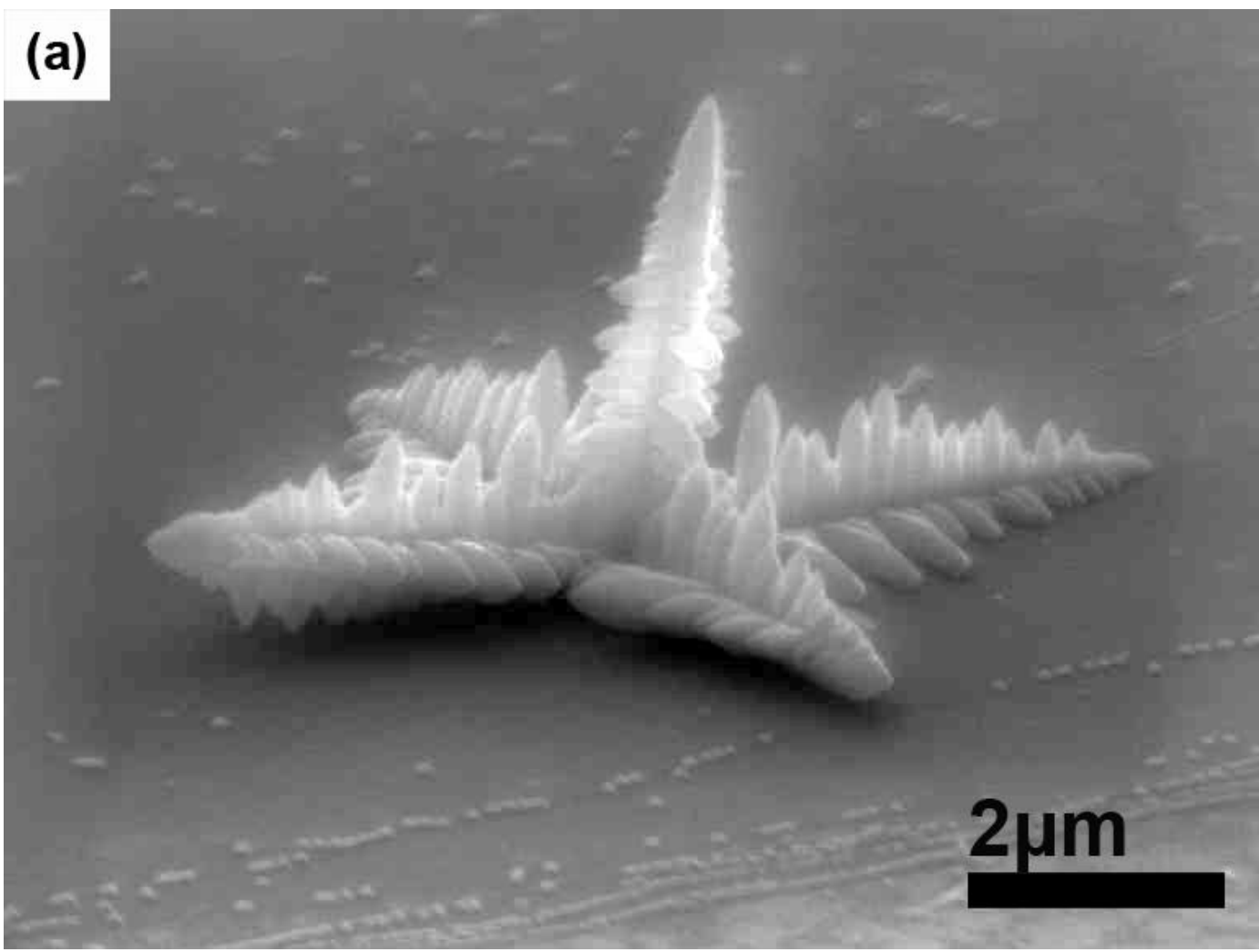

Fig. 10(a)

(b)

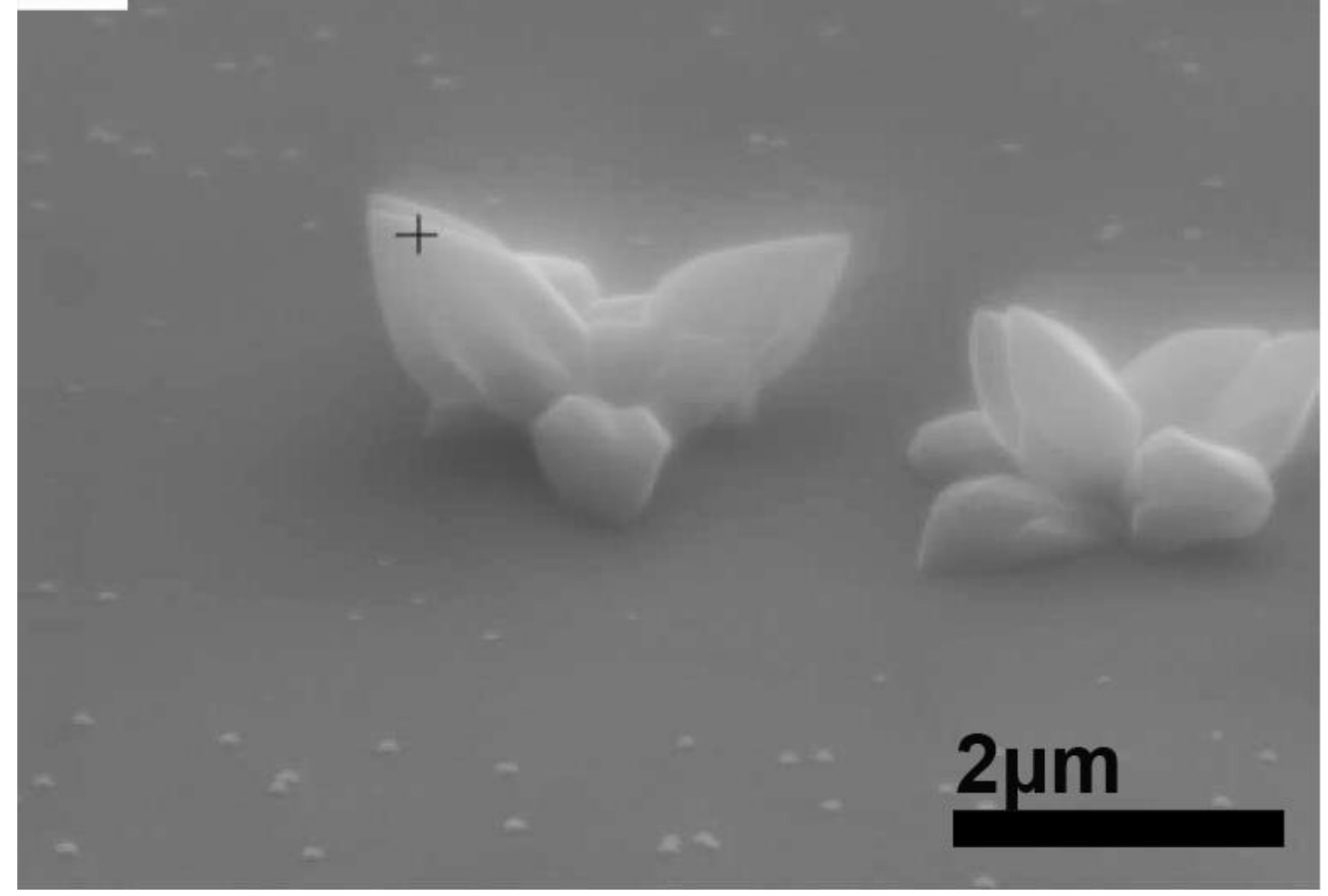

Fig. 10(b) 


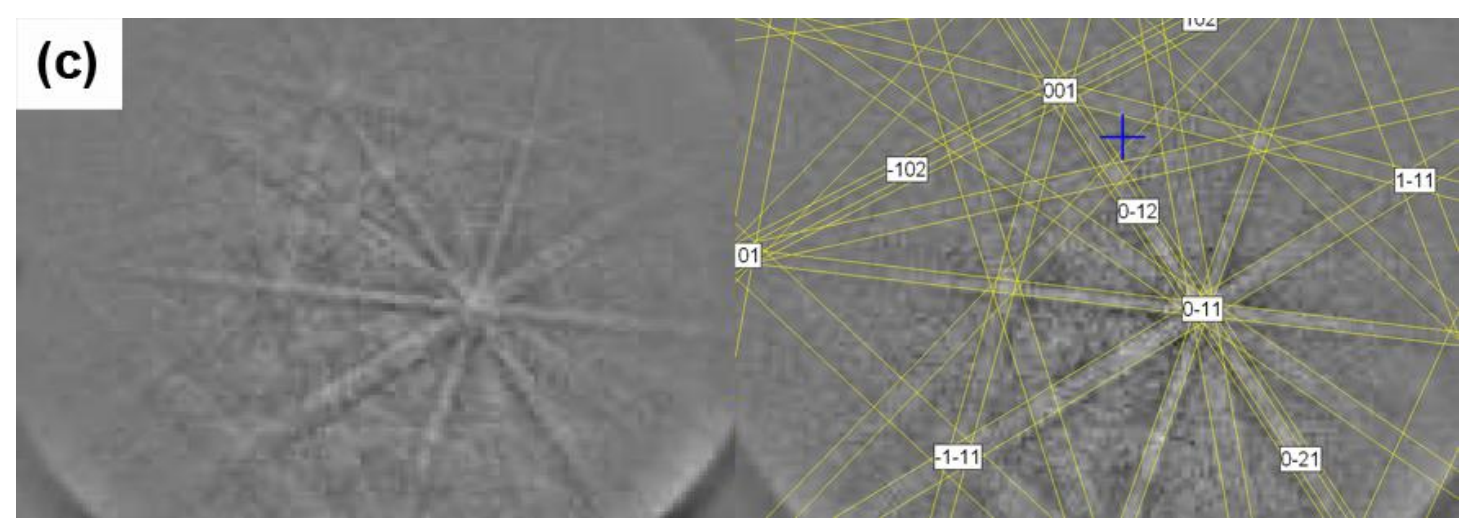

Fig.10(c)

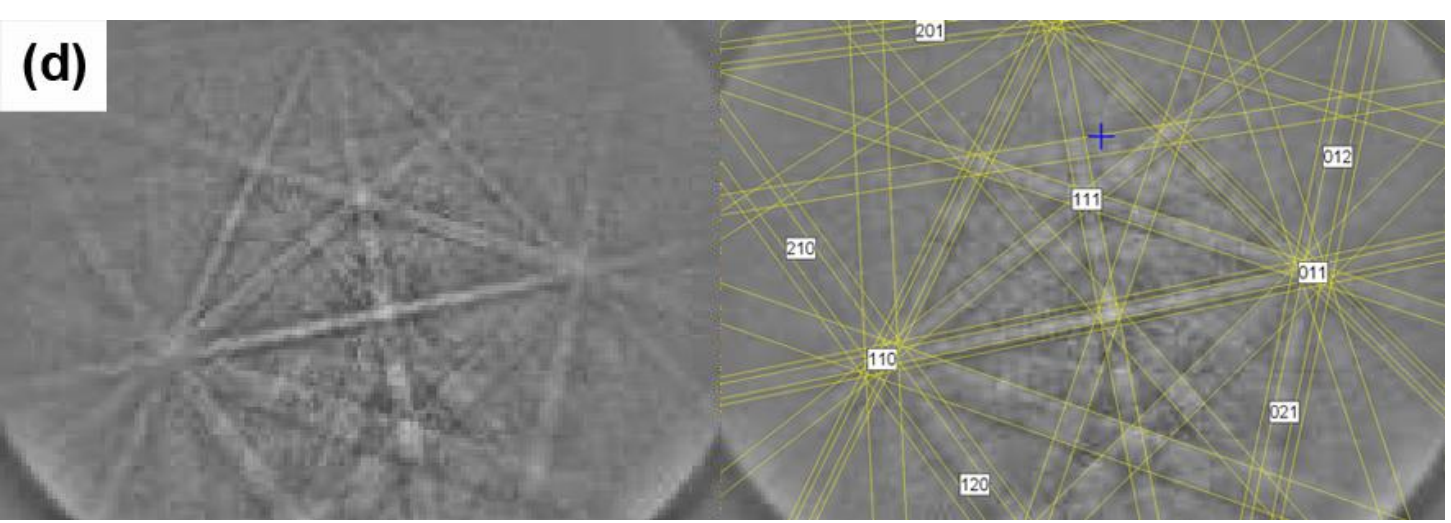

Fig. 10(d)

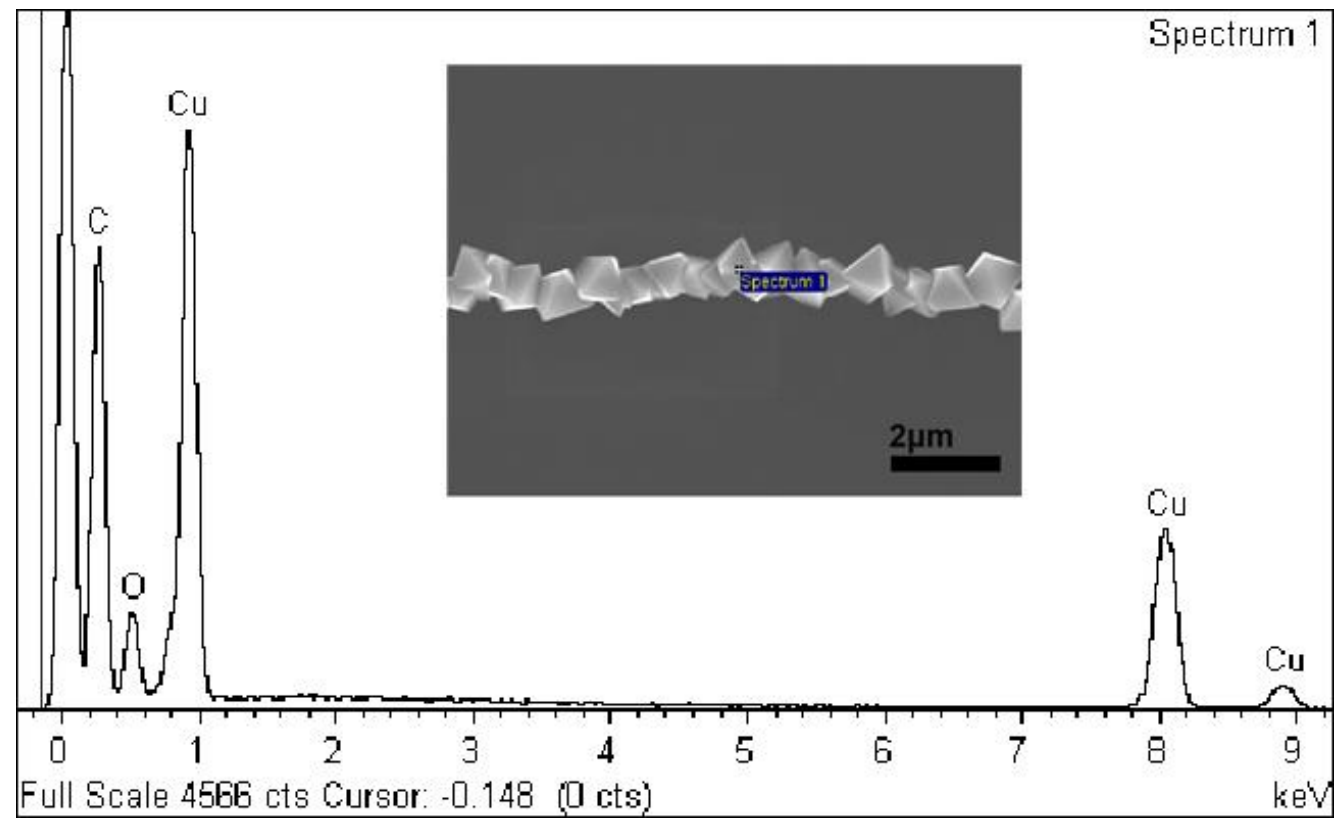

Fig. 11 


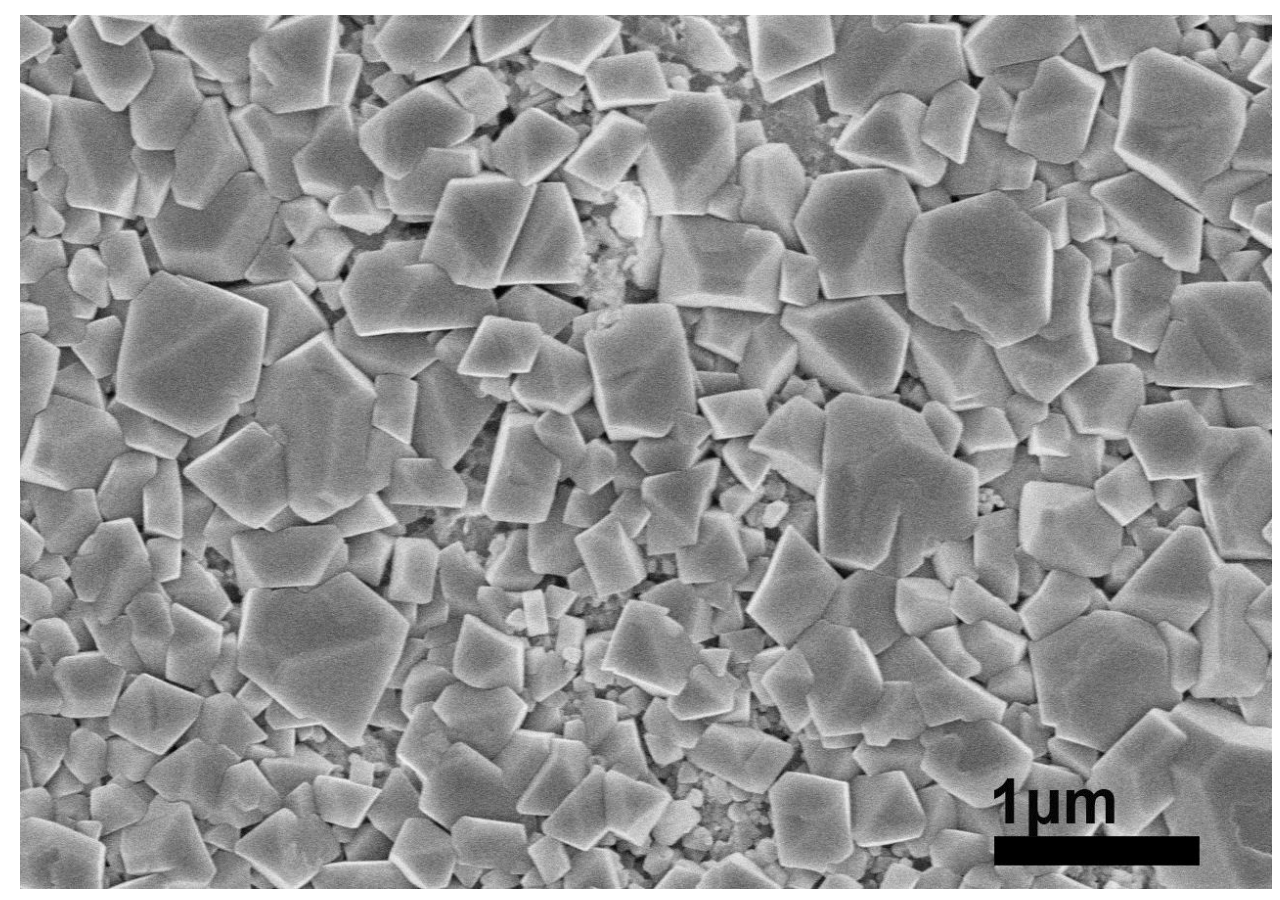

Fig. 12

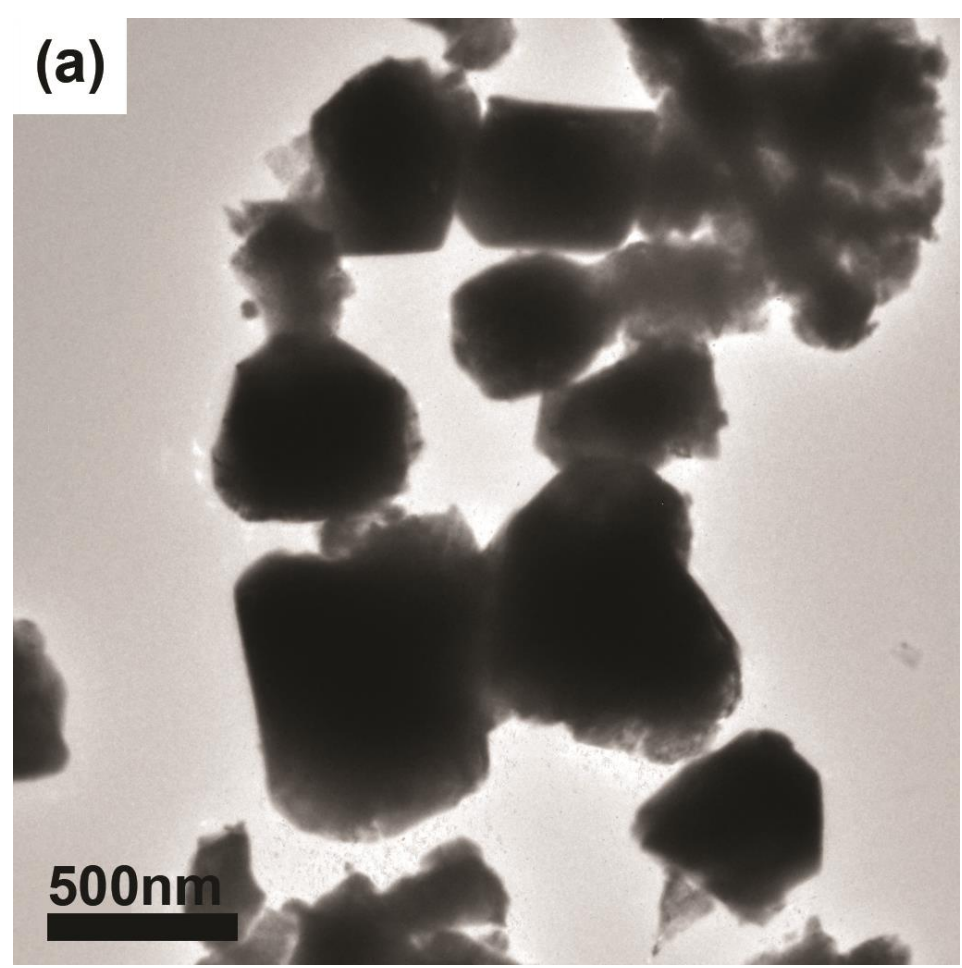

Fig. 13 (a) 


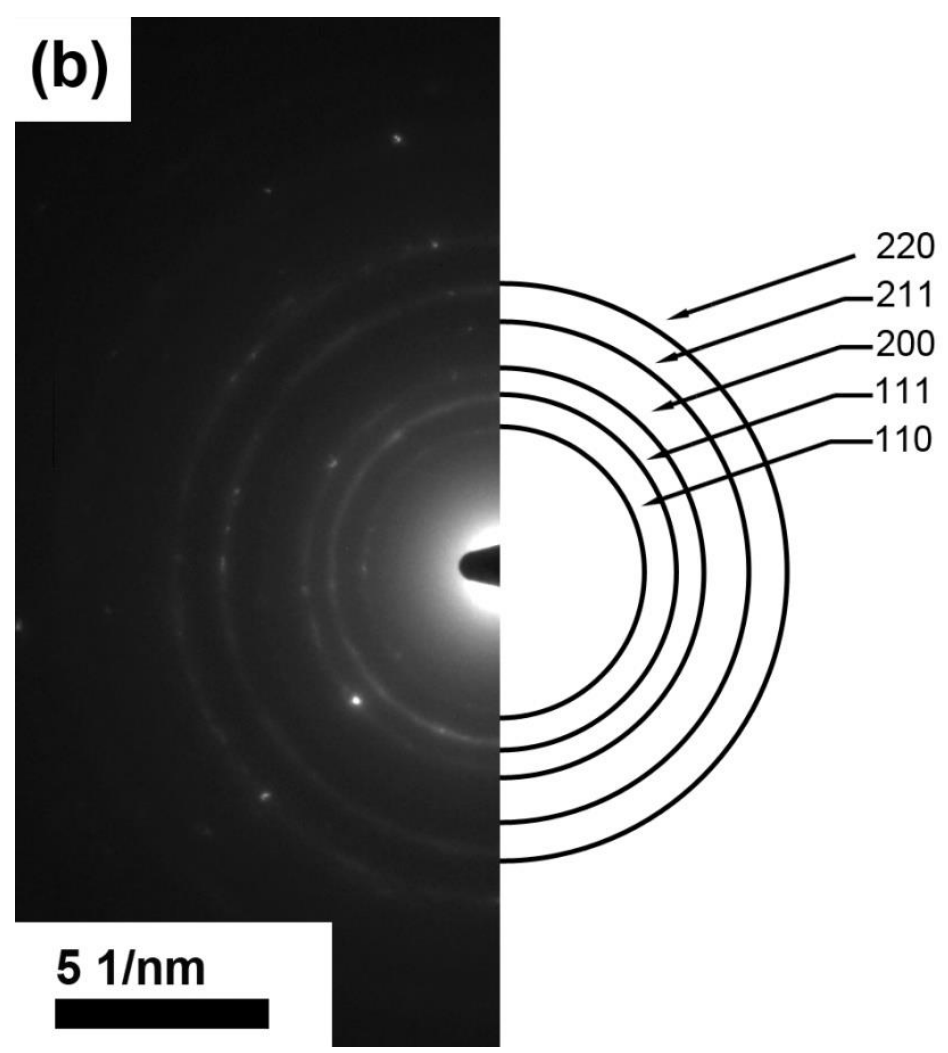

Fig. 13 (b) 